\title{
An 8-Week Self-Administered At-Home Behavioral Skills-Based Virtual Reality Program for Chronic Low Back Pain: Double-Blind, Randomized, Placebo-Controlled Trial Conducted During COVID-19
}

Laura M Garcia ${ }^{1}$, PhD; Brandon J Birckhead ${ }^{1}$, MD, MHDS; Parthasarathy Krishnamurthy ${ }^{2}$, MBA, PhD; Josh Sackman ${ }^{1}$, MBA; Ian G Mackey ${ }^{1}$, BA; Robert G Louis ${ }^{3}$, MD; Vafi Salmasi ${ }^{4}$, MD, MSc; Todd Maddox ${ }^{1}$, PhD; Beth D Darnall ${ }^{4}$, $\mathrm{PhD}$

\footnotetext{
${ }^{1}$ AppliedVR, Inc, Los Angeles, CA, United States

${ }^{2}$ CT Bauer College of Business, University of Houston, Houston, TX, United States

${ }^{3}$ Division of Neurosurgery, Pickup Family Neurosciences Institute, Hoag Memorial Hospital, Newport Beach, CA, United States

${ }^{4}$ Department of Anesthesiology, Perioperative and Pain Medicine, Stanford University School of Medicine, Palo Alto, CA, United States
}

\section{Corresponding Author:}

Beth D Darnall, PhD

Department of Anesthesiology, Perioperative and Pain Medicine

Stanford University School of Medicine

1070 Arastradero Road

Ste 200, MC5596

Palo Alto, CA, 94304

United States

Phone: 115035778377

Email: bdarnall@stanford.edu

\begin{abstract}
Background: Chronic low back pain is the most prevalent chronic pain condition worldwide and access to behavioral pain treatment is limited. Virtual reality (VR) is an immersive technology that may provide effective behavioral therapeutics for chronic pain.

Objective: We aimed to conduct a double-blind, parallel-arm, single-cohort, remote, randomized placebo-controlled trial for a self-administered behavioral skills-based VR program in community-based individuals with self-reported chronic low back pain during the COVID-19 pandemic.

Methods: A national online convenience sample of individuals with self-reported nonmalignant low back pain with duration of 6 months or more and with average pain intensity of 4 or more/10 was enrolled and randomized 1:1 to 1 of 2 daily (56-day) VR programs: (1) EaseVRx (immersive pain relief skills VR program); or (2) Sham VR (2D nature content delivered in a VR headset). Objective device use data and self-reported data were collected. The primary outcomes were the between-group effect of EaseVRx versus Sham VR across time points, and the between-within interaction effect representing the change in average pain intensity and pain-related interference with activity, stress, mood, and sleep over time (baseline to end-of-treatment at day 56). Secondary outcomes were global impression of change and change in physical function, sleep disturbance, pain self-efficacy, pain catastrophizing, pain acceptance, pain medication use, and user satisfaction. Analytic methods included intention-to-treat and a mixed-model framework.

Results: The study sample was 179 adults (female: $76.5 \%, 137 / 179$; Caucasian: 90.5\%, 162/179; at least some college education: 91.1\%, 163/179; mean age: 51.5 years [SD 13.1]; average pain intensity: 5/10 [SD 1.2]; back pain duration $\geq 5$ years: $67 \%$, 120/179). No group differences were found for any baseline variable or treatment engagement. User satisfaction ratings were higher for EaseVRx versus Sham VR $(P<.001)$. For the between-groups factor, EaseVRx was superior to Sham VR for all primary outcomes (highest $P$ value $=.009$ ), and between-groups Cohen $\mathrm{d}$ effect sizes ranged from 0.40 to 0.49 , indicating superiority was moderately clinically meaningful. For EaseVRx, large pre-post effect sizes ranged from 1.17 to 1.3 and met moderate to substantial clinical importance for reduced pain intensity and pain-related interference with activity, mood, and stress. Between-group comparisons for Physical Function and Sleep Disturbance showed superiority for the EaseVRx group versus the Sham VR group
\end{abstract}


$(P=.022$ and .013 , respectively). Pain catastrophizing, pain self-efficacy, pain acceptance, prescription opioid use (morphine milligram equivalent) did not reach statistical significance for either group. Use of over-the-counter analgesic use was reduced for EaseVRx $(P<.01)$ but not for Sham VR.

Conclusions: EaseVRx had high user satisfaction and superior and clinically meaningful symptom reduction for average pain intensity and pain-related interference with activity, mood, and stress compared to sham VR. Additional research is needed to determine durability of treatment effects and to characterize mechanisms of treatment effects. Home-based VR may expand access to effective and on-demand nonpharmacologic treatment for chronic low back pain.

Trial Registration: ClinicalTrials.gov NCT04415177; https://clinicaltrials.gov/ct2/show/NCT04415177

International Registered Report Identifier (IRRID): RR2-10.2196/25291

(J Med Internet Res 2021;23(2):e26292) doi: 10.2196/26292

\section{KEYWORDS}

virtual reality; low back pain; opioids; chronic pain; behavioral health; pain treatment, randomized controlled trial; COVID-19

\section{Introduction}

Chronic low back pain (cLBP) is the most prevalent chronic pain condition worldwide [1]. cLBP can be disabling, costly, and confer suffering to individuals and their families. The incidence and prevalence of cLBP continue to rise despite increasing use of medical treatments such as pharmacology and surgical procedures [2].

An expert evidence review and consensus panel recommended pain education and cognitive behavioral therapy (CBT) as first-line treatments for cLBP [3] with both modalities supplying self-help information for back pain. Beyond the context of back pain, the Centers for Disease Control and Prevention [4] (CDC) and the Centers for Medicare \& Medicaid Services (CMS) [5] have recommended nonpharmacologic therapies as first-line treatments for chronic pain, with the latter citing a need to improve patient access to effective treatment options.

CBT for chronic pain engages participants in active pain and symptom self-management [4,6,7]. In group settings, CBT is delivered by trained therapists and typically involves 8-12 two-hour treatment sessions (16-24 hours total treatment time). Manualized session content includes health and pain education; skills training in goal setting, problem solving and action planning; self-regulatory techniques (eg, relaxation, mindfulness); cognitive techniques (eg, thought monitoring and restructuring unhelpful thoughts); and functional goal setting. While CBT has not shown efficacy for reducing pain intensity, it has small to moderate effects for reducing depressive symptoms [7], pain bothersomeness [6,7], and pain catastrophizing [6,7] (Darnall et al, unpublished data) in mixed etiology chronic pain as well as cLBP. Despite demonstrated efficacy for these multisession behavioral pain treatments, access to care remains poor due to barriers such as few trained and available local therapists, health insurance limits, and burdens associated with travel and treatment time [8]. Because of the scope and impact of cLBP, there is an urgent need for effective, accessible, low-risk treatments that are acceptable to people who have back pain. Improved access to behavioral pain care is particularly salient within the context of reduced opioid prescribing for chronic pain nationally [9].

On-demand digital therapeutics may provide home-based access to pain education and skills-based pain self-management.
Particularly during the COVID-19 pandemic, home-based behavioral pain care has gained interest, importance, and engagement among patients [10]. Home-based digital pain treatment options include those involving therapist instruction [11,12] (Ziadni et al, unpublished data), as well as fully automated behavioral programs. For the latter, the portfolio of self-treatment options includes computer applications for symptom tracking, education, and treatment [13]; web-based programs that include self-paced multisession skills-based pain management learning modules [14]; and virtual reality (VR) immersive treatment [15].

VR treatment involves using headset devices that fully restrict the vision field to content displayed inside the headset screen; auditory perception is not fully restricted, though the corresponding device-delivered auditory content commands attention. As a treatment modality, VR provides a unique environment comprising 3D visually immersive experiences that are enriched with stereo sounds and elements such as rich colors and scenic environments that enhance elicitation of desired states of arousal and affect. Within the therapeutic context, VR may be flexibly designed and tailored to address the needs of specific conditions (eg, anxiety, depression, pain) [15-19]. The multisensory immersive VR environment stimulates the visual, auditory, and proprioceptive senses, thus engendering the perception that the user is physically located within the virtual environment they are viewing in the headset [20,21]. Mechanistically, the integrated, multisensory, and immersive properties of VR are thought to enhance treatment effects. For example, results from phobia treatment research has suggested noninferiority of VR treatment compared to treatment with a live therapist [18].

In terms of pain, evidence from multiple independent research groups suggests that VR is effective for managing acute pain [22], including pain evoked during medical procedures [23-28], burn wound care [29,30], and in hospitalized patients [31,32]. Researchers of a randomized controlled trial (RCT) conducted in hospitalized patients found that VR yielded the highest efficacy in patients reporting the most severe pain $(\geq 7 / 10)$, thereby underscoring its potent analgesic potential [31].

The scientific literature on VR for chronic pain includes studies conducted in complex regional pain syndrome [33], chronic headache/migraine [34], fibromyalgia [35,36], and chronic 
musculoskeletal pain [37,38]. Two recent reviews and meta-analyses reported VR efficacy for reducing pain and disability (physical rehabilitation) for painful spinal conditions [39] and for orthopedic rehabilitation [40]. Such rehabilitation studies may apply interactive VR in isolation or with kinematic training [41,42]. In addition to small sample sizes, the literature for VR in chronic pain remains limited by studies conducted in experimental or clinical settings (versus home-based and pragmatic studies), a lack of placebo-controlled studies, and studies that have yielded low-quality evidence [39]. Additionally, the literature has been largely restricted to VR content involving distraction or physical rehabilitation and kinematic exercises with little or no content on active behavioral pain management skills acquisition. To address several of these evidence gaps, our group recently conducted an RCT of a 21-day VR program that included chronic pain education and pain relief skills such as diaphragmatic breathing and relaxation response training, and cognition and emotion regulation techniques [15]. Individuals with cLBP or fibromyalgia were randomized to receive either the 21-day VR treatment program or the same treatment content delivered in audio-only format $(\mathrm{N}=74)$. At posttreatment, the VR skills-based treatment group evidenced superior reductions in pain intensity and pain-related interference with activity, sleep, mood, and stress compared to the audio treatment group, with results strengthening after 2 weeks. Similar treatment engagement rates between treatment groups supported a conclusion that the immersive effects of VR yielded superior outcomes [15].

This study builds on this prior work and extends it in several ways. First, the VR treatment program being tested (EaseVRx) is 56 days in length, thereby aligning more with traditional and reimbursable behavioral medicine programs such as 8-week chronic pain CBT or mindfulness programs. Second, the VR content was enriched with interoceptive entrainment techniques designed to enhance biofeedback response and learning. Third, the therapeutic VR program includes expanded pain neuroscience education, as well as principles and elements drawn from CBT, mindfulness, and acceptance-based treatments for chronic pain. Fourth, the study includes a VR sham comparator to control for the novelty of the technology and placebo effects. Fifth, data for analgesic medication use were collected.

Our objective was to conduct a placebo-controlled RCT in community-based individuals with cLBP assigned to receive one of two 56-day treatment programs: therapeutic VR (EaseVRx) or Sham VR [43]. We hypothesized that participants assigned to therapeutic VR would evidence superior outcomes for all baseline to posttreatment comparisons compared to participants assigned to Sham VR.

\section{Methods}

\section{Study Protocol}

The study protocol is published elsewhere and provides additional detail [43]. We conducted a single-cohort, double-blinded (participant and analysts), placebo-controlled randomized clinical trial in an online convenience national sample of community-based individuals with self-reported cLBP. Study participants were participating in a longer study of 8.5 months' duration that involves multiple additional posttreatment assessments not reported here. The study was approved by the Western Institutional Review Board on July 2, 2020, and data collection for this report was completed in November 2020. This report is constrained to the end of treatment time point (day 56).

\section{Study Sample, Setting, Recruitment, and Participant Compensation}

Community-based individuals with cLBP were recruited nationally through chronic pain organizations (eg, American Chronic Pain Association) and through Facebook online advertisements. Additionally, study advertisements were emailed to professional contacts at several medical clinics with requests to forward among medical colleagues nationally. All study advertisements directed interested individuals with cLBP to the study website for information and invitation to complete an automated online eligibility form that screened for inclusion and exclusion criteria (Textbox 1). This screening process was completed over the phone for 1 individual due to technical difficulties. Individuals determined to be eligible for the study were invited to participate in a study examining the effectiveness of an 8-week VR wellness program in helping them manage chronic lower back pain. If willing to participate, participants completed an electronic informed consent (eConsent; see Multimedia Appendix 1 for the study consent form) and provided their e-signature to complete their enrollment in the study. Figure 1 displays the participant study activities.

Enrolled participants completed a baseline survey and then received 3 pain surveys over a 2 -week pretreatment assessment period. Those who completed at least one survey during this pretreatment period progressed to the treatment phase of the study, which included an 8-week VR program (therapeutic VR or Sham VR), twice-weekly surveys during the VR treatment phase, and a final survey administered at treatment completion on day 56. All study procedures occurred remotely.

Study participation was compensated in 2 ways. First, participants received US \$6 per completed survey (US \$126 possible; prorated) in the form of an Amazon eGift Card after the day 56 survey and upon return of their VR headset (prepaid shipping containers were provided). Second, all participants were eligible to receive a gift VR headset 6 months after their completion of treatment if they completed 16 or more study surveys, confirmed their interest in receiving a VR headset, and returned their VR headset. A total of 77 study participants met these criteria and will receive headsets (Textbox 1). 
Textbox 1. Study inclusion and exclusion criteria.

\section{Inclusion criteria}

1. Men and women aged 18-85.

2. Self-reported diagnosis of chronic low back pain without radicular symptoms.

3. Chronic low back pain duration of 6 months or more.

4. Average pain intensity of 4 or more out of 10 for the past month.

5. English fluency.

6. Willing to comply with study procedures/restrictions.

7. Access to Wi-Fi.

8. Implicit de facto internet and computer literacy.

\section{Exclusion criteria}

1. Gross cognitive impairment.

2. Current or prior diagnosis of epilepsy, seizure disorder, dementia, migraines, or other neurological diseases that may prevent the use of virtual reality or adverse effects.

3. Medical condition predisposing to nausea or dizziness.

4. Hypersensitivity to flashing light or motion.

5. No stereoscopic vision or severe hearing impairment.

6. Injury to eyes, face, or neck that impedes comfortable use of virtual reality.

7. Cancer-related pain.

8. Moderate depressive symptoms as indicated by the Patient Health Questionnaire-2 (PHQ-2 [44,45]) depression screen score of 2 or more.

9. Previous use of EaseVRx for pain.

10. Current or recent completion of participation (past 2 months) in any interventional research study.

11. Currently pregnant or planning to become pregnant during the study period.

12. Not expected to have access to Wi-Fi during the study period.

13. Currently works at or has an immediate family member who works for a digital health company or pharmaceutical company that provides treatments for acute or chronic pain. 
Figure 1. Participant activities.

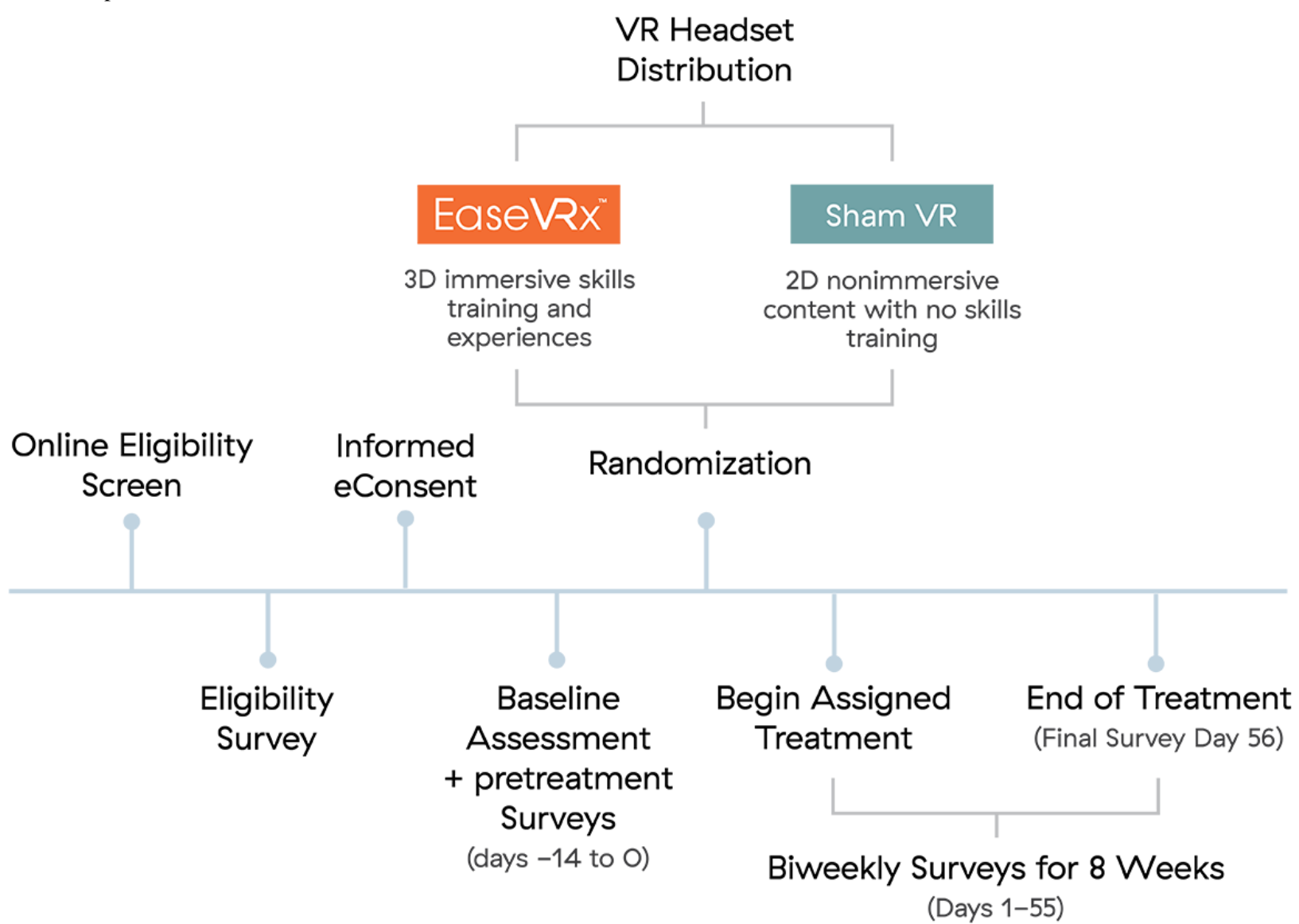

\section{Randomization and Blinding}

Participants were randomized $1: 1$ and allocated to 1 of 2 treatment groups: (1) the 56-day pain relief skills VR program (EaseVRx) or (2) a 56-day control VR condition (Sham VR). REDCap Cloud (nPhase, Inc.) was used to apply an automatic and blinded randomization program and ensure equal allocation to both groups. Participants and study statisticians were blinded to treatment group assignment. Statisticians performed blinded analysis of data sets that were randomly labeled group A and group B with statistician unblinding occurring only after posttreatment month 3 data were collected and the data set locked (posttreatment month 3 data not yet analyzed). The 2 study coordinators (LG and IM) unblinded to individual treatment group assignments were not involved in any data analyses. Study participants remain blinded to treatment group assignment until their participation in the larger study is completed (8.5 months after randomization). The larger study quantifies long-term outcomes for the current treatment study; the study protocol and details are published elsewhere [43].

\section{Study Interventions, VR Headset, and Software}

Participants in both treatment groups (EaseVRx and Sham VR) received a Pico G2 4K all-in-one head-mounted VR device at no cost through postal mail. The Pico G2 4K device was used because they are commercially available, widely used, inexpensive, have minimal visual latency, and are easier for participants to use than many other devices. This hardware allows for displaying 3D images (EaseVRx) and 2D images
(Sham VR). While each VR device contained software specific to the individual participant's assigned VR treatment group, all device packaging and directions for use were common to both treatment groups. Participants in this study were provided with online access to instructional materials outlining general use and set up of the headset. Relevant to the EaseVRx group, user exhalation is measured by the microphone embedded in the Pico G2 hardware, offering biodata-enabled immersive therapeutics. Participants in both groups were instructed to complete 1 VR program session daily for 56 days. Study staff monitored participant completion of the twice-weekly surveys and device use. Study staff provided reminders to complete surveys and otherwise were available upon request for technical support. The sections below describe the elements of the study interventions.

\section{Therapeutic VR (EaseVRx)}

Participants randomized and allocated to this treatment group received an immersive multimodal, skills-based, pain self-management VR program, called EaseVRx (AppliedVR), that incorporates evidence-based principles of CBT, mindfulness, and pain neuroscience education. The program content trains users on evidence-based pain and stress management strategies via immersive and enhanced biofeedback experiences. EaseVRx combines biopsychosocial education, diaphragmatic breathing training, relaxation response exercises that activate the parasympathetic nervous system, and executive functioning games to provide a mind-body approach toward living better with chronic pain. The standardized 56-day program 
delivers a multifaceted combination of pain relief skills training through a prescribed sequence of daily immersive experiences. Each VR experience is 2-16 minutes in length (average of 6 minutes). The VR treatment modules were designed to minimize triggers of emotional distress or cybersickness. Treatment module categories included:

- Pain education: visual and voice-guided lessons establish a medical and scientific rationale for the VR exercises and behavioral medicine skills for pain relief.

- Relaxation/Interoception: scenes that progressively change from busy/active to calm in order to train users to understand the benefits of progressive relaxation.

- Mindful escapes: high-resolution 360 videos with therapeutic voiceovers, music, guided breathing, and sound effects designed to maximize the relaxation response and participant engagement.

- Pain distraction games: interactive games to train the skill of shifting focus away from pain.
- Dynamic breathing: breathing-based biofeedback training in immersive and interactive environments to support self-regulation and relaxation. These modules become increasingly challenging as users increase their skill with diaphragmatic breathing and parasympathetic control.

\section{Sham VR}

In compliance with VR-CORE clinical trial guidelines, we selected an active control that utilizes nonimmersive, 2D content within a VR headset as the most rigorous VR placebo [30]. The Sham VR headset displayed 2D nature footage (eg, wildlife in the savannah) with neutral music that was selected to be neither overly relaxing, aversive, nor distracting. The experience of Sham VR is similar to viewing nature scenes on a large-screen television and is not interactive. Twenty videos were rotated over the 56 sessions, with average duration of sessions closely matching those of EaseVRx (Figure 2).

Figure 2. Visual display of EaseVRx (skills-based, interactive, 3D) and Sham VR (non-interactive 2D nature scenes).

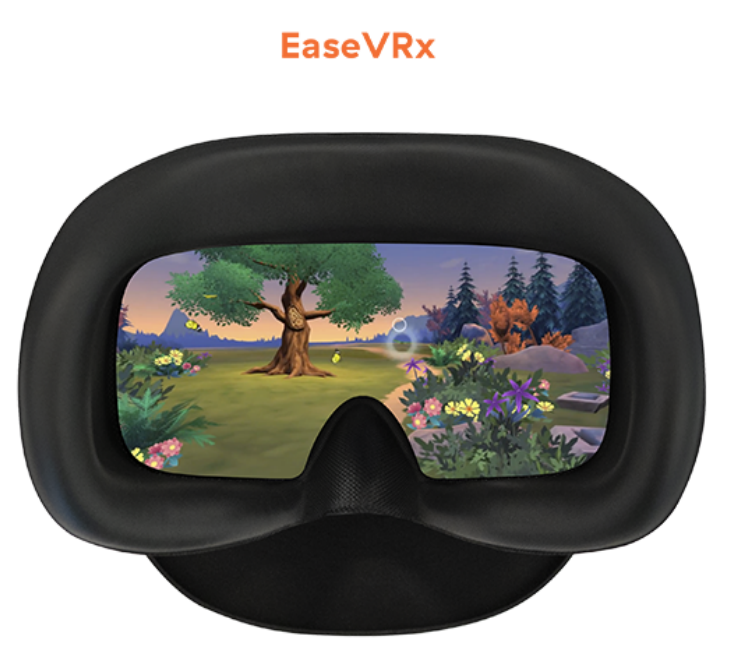

\section{Research Standards and Compliance}

In accordance with the Initiative on Methods, Measurement, and Pain Assessment in Clinical Trials (IMMPACT) recommendations, we included multiple measures to evaluate the importance of change in outcomes across 4 recommended domains: pain intensity, health-related quality of life and functioning, and ratings of overall improvement [46-48]. Additionally, measures and individual items were included to align directly with the National Institutes of Health (NIH) Pain Consortium's Report on Research Standards for Chronic Low Back Pain [49] or assess the domains recommended in the report. The study was performed in accordance with the CONSORT (Consolidated Standards of Reporting Trials) guidelines [50] (see Multimedia Appendix 2 for the completed checklist) and the recommended extension for reporting of

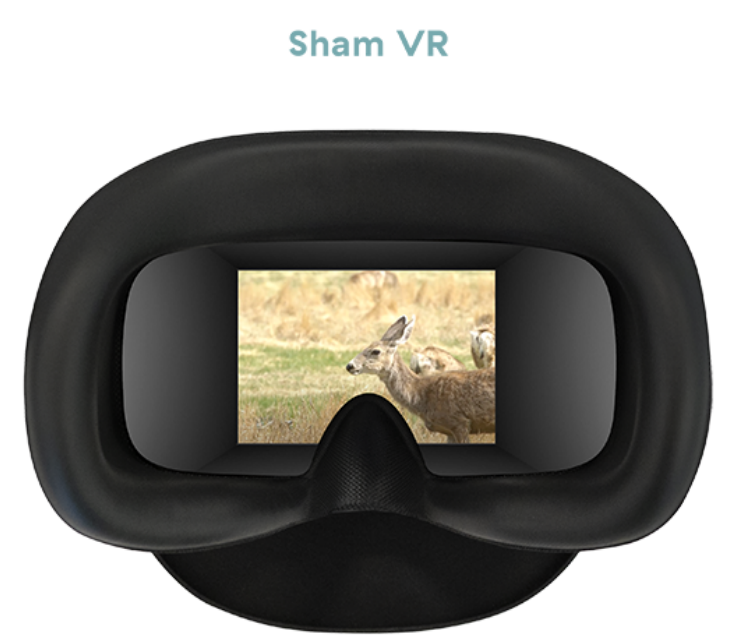

psychological trials [51]. The Western Institutional Review Board approved the study (Puyallup, WA).

\section{Data Collection and Time Points}

Data collection included electronic participant-reported measures and objective VR device use data collected from the VR devices.

Data were collected across 3 phases of the study: pretreatment (days -14 to 0 ), active treatment (days 1-55), and end of treatment (day 56). The 14-day pretreatment phase involved administering the pain surveys 5 times (baseline, days $-10,-7$, -3 , and 0 ); these measures were averaged within participants to establish a single pretreatment score for each variable assessed. During the 8-week active treatment phase, surveys were distributed biweekly (15 total surveys during treatment) 
and at end of treatment on day 56. Accordingly, there were 17 time points per participant.

\section{Study Variables and Measures}

Table 1 outlines the timeline of variable assessment. This section details the measurement and methods used to assess each variable.

Table 1. Timeline of variable assessment.

\begin{tabular}{|c|c|c|c|c|}
\hline \multirow[t]{2}{*}{ Variables } & \multicolumn{2}{|c|}{ Pretreatment phase (Days -14 to 0 ) } & \multirow{2}{*}{$\begin{array}{l}\text { Treatment phase (Days } 1 \text { to } 55 \text { ) } \\
\text { Biweekly surveys }\end{array}$} & \multirow{2}{*}{$\begin{array}{l}\text { End-of-treatment (Day 56) } \\
\text { Final assessment }\end{array}$} \\
\hline & Baseline & Biweekly surveys & & \\
\hline Demographics and pain duration & $\mathrm{X}$ & & & \\
\hline Pain intensity & $\mathrm{X}$ & $X$ & $\mathrm{X}$ & $\mathrm{X}$ \\
\hline $\begin{array}{l}\text { Pain interference with activity, mood, } \\
\text { sleep, stress }\end{array}$ & $\mathrm{X}$ & $\mathrm{X}$ & $\mathrm{X}$ & $\mathrm{X}$ \\
\hline Patient's Global Impression of Change & & & & $\mathrm{X}$ \\
\hline Physical function & $\mathrm{X}$ & & & $\mathrm{X}$ \\
\hline Sleep disturbance & $\mathrm{X}$ & & & $\mathrm{X}$ \\
\hline Pain self-efficacy & $\mathrm{X}$ & & & $\mathrm{X}$ \\
\hline Pain catastrophizing & $\mathrm{X}$ & & & $\mathrm{X}$ \\
\hline Chronic pain acceptance & $\mathrm{X}$ & & & $\mathrm{X}$ \\
\hline Prescription opioid use & $\mathrm{X}$ & & & $\mathrm{X}^{\mathrm{a}}$ \\
\hline $\begin{array}{l}\text { Over-the-counter analgesic medication } \\
\text { use }\end{array}$ & & & & $\mathrm{X}$ \\
\hline Motion sickness and nausea & & & & $X^{\mathrm{a}}$ \\
\hline Treatment satisfaction & & & & $X^{\mathrm{a}}$ \\
\hline Virtual reality device use & & & $\mathrm{X}$ & $\mathrm{X}$ \\
\hline System usability & & & & $\mathrm{X}$ \\
\hline
\end{tabular}

${ }^{\mathrm{a}}$ Because of a system error, these data were not captured at Day 56 as intended but at 1-month posttreatment.

\section{Demographics and Pain Duration}

Demographic variables included age, gender, level of education, race, ethnicity, employment status, annual household income, relationship status, duration of back pain (years since onset), state of residence, and zip code. To perform geospatial coding, rural-urban commuting area (RUCA) codes were downloaded from a public data set provided by the United States Department of Agriculture Economic Research Service [52]. Participants were classified as rural or urban based on their zip code. Finally, duration of time since pain onset was assessed.

\section{Average Pain Intensity}

The Defense and Veterans Pain Rating Scale (DVPRS) [53] was used to measure average pain intensity over the previous 24 hours using an 11-point numeric rating scale $(0=$ no pain; $10=$ as bad as it could be and nothing else matters). Average pain intensity was assessed at baseline, pretreatment, during treatment, and at end of treatment on day 56.

\section{Pain Interference With Activity, Mood, Sleep, and Stress}

The DVPRS interference scale (DVPRS-II) was used to measure pain interference with activity, sleep, mood, and stress over the past 24 hours [54] $(0=$ does not interfere; 10=completely interferes). Pain interference was assessed at baseline, pretreatment, during treatment, and at end of treatment on day 56.

\section{Patient's Global Impression of Change}

Aligning with IMMPACT recommendations for pain research [47], Patient's Global Impression of Change (PGIC) was assessed on day 56 (end of treatment) using the question, "Since the beginning of VR treatment, how would you describe the changes (if any) in activity limitations, symptoms, emotions and overall quality of life related to your low back pain?" on a 7-point scale ranging from 1 (No change or condition is worse) to 7 (A great deal better, and a considerable improvement that has made all the difference).

\section{Physical Function and Sleep Disturbance (PROMIS)}

The NIH Physical Function and Sleep Disturbance (PROMIS) [55] short-form measures were used to assess physical function (version 6b) [56] and sleep disturbance (version 6a) [57] over the past 7 days. Higher scores on physical function signify greater function whereas higher scores for sleep disturbance reflect greater symptom severity. The conversion table within the scoring manuals, made available from the Person-Centered Assessment Resource [58,59], was used to calculate the individual short-form $\mathrm{T}$ scores using the Item Response Theory scoring algorithms. Specifically, based on published item 
parameters, $\mathrm{T}$ scores (latent trait estimates) are computed for each individual's response pattern using the Bayesian expected a posteriori method [60-62]. Widely applied in pain research [63-65], these measures were administered at baseline and posttreatment day 56.

\section{Pain Catastrophizing}

The 13-item Pain Catastrophizing Scale (PCS) [66] is a validated instrument widely used clinically and in pain research to assess patterns of negative cognition and emotion in the context of actual or anticipated pain. Despite having discrete subscales for rumination, magnification, and feelings of helplessness related to pain, prior work has shown that the PCS operates unidimensionally [67] (Cook et al, unpublished data). Aligning with prior work [15] and the goal of brevity, the following 4 PCS items were used: "It's terrible and I think it's never going to get any better," "I become afraid that the pain will get worse," "I can't seem to keep it out of my mind," and "I keep thinking about how badly I want the pain to stop." Respondents rate the frequency with which they experience such thoughts on a scale from 0 (Not at all) to 4 (All the time). Scores for the 4 items were summed to create a total score and index for pain catastrophizing. This measure was administered at baseline and on day 56.

\section{Pain Self-Efficacy}

Pain self-efficacy was assessed generally and also within the context of VR. For general pain self-efficacy, the 2-item Pain Self-Efficacy Questionnaire (PSEQ-2) is a validated instrument used to assess respondents' confidence in their ability to engage in various daily activities despite their chronic pain [68]. The PSEQ-2 comprises the following 2 items: "I can still accomplish most of my goals in life, despite the pain," and "I can live a normal lifestyle, despite the pain." Respondents use a 5-point scale to rate their response from 0 (Not at all confident) to 4 (Completely confident). Scores for the 2 items are summed to create a total score. The PSEQ-2 was administered at baseline and on day 56. For pain self-efficacy with a VR referent, at baseline, participants rated their overall confidence in their ability to manage their pain on a 10-point scale from 1 (Not at all Confident) to 10 (Very Confident). Following the intervention, this section will be divided into 2 items measuring their overall confidence levels while inside VR and outside VR.

\section{Chronic Pain Acceptance}

The 8-item Chronic Pain Acceptance Questionnaire (CPAQ-8) short form is an 8-item validated instrument that assesses one's engagement in personally meaningful activities despite pain, as well as efforts directed at controlling pain (example item: "I am getting on with the business of living no matter what my level of pain is") [69]. Respondents rate each item using a 6-point scale ranging from 0 (never true) to 5 (always true).

\section{Satisfaction With Treatment}

Satisfaction with treatment was assessed with several items. First, using a 6-point scale ( $0=$ strongly disagree and 5=strongly agree), participants rated 4 items: ease of use of the VR headset, enjoyment of the headset, whether the headset helped with pain coping, and desire to continue using the VR headset. These 4 items were summed to create a total satisfaction score.
Additionally, 1 item assessed likelihood to recommend VR $(0=$ definitely not recommend and $10=$ definitely would recommend). One item assessed likelihood to continue using VR if they were able to keep their headset using a response scale $(0=$ definitely would not it and $10=$ definitely would use it). Because of an error with the electronic survey administration, these data were captured at 1 month posttreatment.

\section{VR Device Use}

Device use data were recorded by the devices (date and time stamped for device access and duration of use).

\section{System Usability Scale}

The System Usability Scale (SUS) is a validated, 10-item scale to assess a global view system usability (example item: "I thought the system was easy to use") [70]. Participants rate each item using a 5-point response scale ranging from $1=$ strongly disagree to 5=strongly agree. Some items are reverse scored, a multiplier is applied to the sum total, and total SUS scores range from $0-100$.

\section{Motion Sickness and Nausea (Cybersickness)}

Adverse experiences with using VR was assessed using the question, "Did you experience any motion sickness or nausea while using VR?" on a 4-point scale, with $0=$ Never, 1=Sometimes, 2=Often, and 3=Always. Similar to prior work, cybersickness was assessed at the end of treatment [15]. Because of an error with the electronic survey administration, these data were captured at 1-month posttreatment.

\section{Over-the-Counter Analgesic Medication Use}

Participants were asked, "Do you take any 'over the counter' medication, meaning you can get yourself at a store without a prescription, to help you manage your back pain?" A binary response set $(\mathrm{Y} / \mathrm{N})$ was used to address variability in medication classes, formulations, doses, and frequency of use. Over-the-counter (OTC) analgesic use was measured at baseline and at posttreatment day 56.

\section{Opioid Use Data}

All opioid data were self-reported. Opioid medication doses were converted to a standardized morphine milligram equivalent daily dose using the Centers for Medicare \& Medicaid Services "Opioid Oral Morphine Milligram Equivalent (MME) Conversion Table" [71]. Four assumptions were applied universally to all participants in calculating prescribed medication doses. First, participants who reported prescription medication use but did not report any of the classes of prescription medications were considered opioid free. Second, for participants who did not report the strength of their tablets, the most common dose of the tablet was used for the calculations (Hydrocodone $5 \mathrm{mg}$, Hydromorphone $2 \mathrm{mg}$, Oxycodone $5 \mathrm{mg}$, and Tramadol $50 \mathrm{mg}$ ); these doses are the lowest strength available for these medications and thus provide conservative estimates. Third, some participants reported using opioids "as needed" (ie, pro re nata [PRN] use) but did not detail their general frequency of use. For these cases, we calculated the dose and range based on 0 to maximum daily allowed (eg, for a participant prescribed medication every 6 hours PRN, we used the allowable range of 0-4 tablets per day and used the average 
value of 2 tablets per day). Fourth and last, if participants reported their frequency of opioid use to be weekly, the reported dose was divided by 7 for calculating a daily MME; similarly, monthly reported doses were divided by 30 to calculate a daily MME.

\section{Adverse Event Monitoring}

Participants were provided with study staff contact information and encouraged to contact as needed and in the event of any problems using their device or with their treatment. Similar to other studies, cybersickness was assessed at the end of treatment [15]. However, due to a problem with the electronic survey, these data were not captured, and the survey was re-administered at 1-month posttreatment.

\section{Sample Size Determination}

A power analysis was performed using data from a prior RCT of a 21-day at-home VR for chronic pain compared to an audio-only version of the treatment [15]. This study revealed that an average pre-post treatment difference score in pain intensity was 1.48 for the VR group and 0.756 for the audio-only group (on an 11-point scale). Assuming an $\alpha$ level of .05 and $90 \%$ power, 45 participants per group would detect a treatment group $\times$ time interaction. To buffer against potential high attrition (40\%), a minimum of 75 participants would be required per treatment group, with 90 participants per treatment group being ideal.

\section{Statistical Analyses}

All analyses involved 2-sided hypothesis tests, with $\alpha=.05$ and adjusted for any multiple comparisons within the family of tests as appropriate. Group equivalence was assessed through univariate tests of association between treatment groups (EaseVRx/Sham VR) for all baseline demographic and clinical variables with chi-square and Kruskal-Wallis applied as appropriate.

The data were analyzed in a mixed-model framework (PROC GLIMMIX in SAS) using a marginal (population-averaged) model to allow for correlated responses across the repeated measures. There were 3 explanatory factors: treatment group, time, and time $\times$ treatment group. Treatment group, EaseVRx versus Sham VR, was specified as a fixed-effects factor. Time was specified as a random-effects factor to allow for correlated response using heterogeneous compound symmetry for the covariance structure within time. The 2 effects of interest were
(1) the EaseVRx versus Sham VR between-group comparison across all time points, and (2) the time $\times$ treatment group effect which tests whether the treatment group influenced the trajectory of the key variables over time.

Data were $95.05 \%$ complete; missing values were not imputed for estimation of effects, but the predicted means were used in the graphical description. The primary outcomes were the time course of DVPRS (pain scale) from baseline (defined as the average of 3 pain ratings obtained during the 2 weeks before enrollment/randomization), at 8 weekly time points (twice per week) across the 8-week treatment period, and immediately posttreatment (Day 56). A linear mixed model was used with the treatment group (EaseVRx versus Sham VR) as an independent groups factor (ie, a between-subjects factor) and time of measurement as a dependent groups factor (ie, a within-subjects factor). DVPRS-II measures were analyzed using the same approach. Effect sizes for the EaseVRx versus Sham VR for the between-groups comparison were calculated using the standardized mean difference version of Cohen $d$ [72]. The effect sizes for the within-subjects comparison (baseline to immediately posttreatment completion at day 56) were computed by treatment group using $d_{r m}$, an adaptation of Cohen $d$ to suit the repeated measures design [73].

\section{Results}

\section{Study Participants}

Figure 3 shows the CONSORT diagram for the study (see Multimedia Appendix 2 for the CONSORT checklist). In total, 1577 individuals were assessed for eligibility and 1389 were excluded with the primary reason of having met the threshold for depressive symptoms. A total of 188 individuals were enrolled, randomized, and allocated to the treatment group. After randomization, 9 individuals discontinued participation, 5 were unable to receive a VR device, 1 returned their unopened device due to a recent medical diagnosis, and 4 voluntarily withdrew for unknown reasons. A total of 179 individuals received a VR device with their assigned treatment (EaseVRx [ $n=89]$ or Sham VR [ $n=90]$ ). Because intention-to-treat analyses were performed, the analytic data set includes 11 individuals who did not provide complete data. Nearly $94 \%$ of participants in group A (84/89) and 93\% of participants in group B (84/90) completed the day 56 assessment (end of treatment). 
Figure 3. CONSORT Flow Diagram.

\section{CONSORT Flow Diagram Virtual Reality for Chronic Low Back Pain}

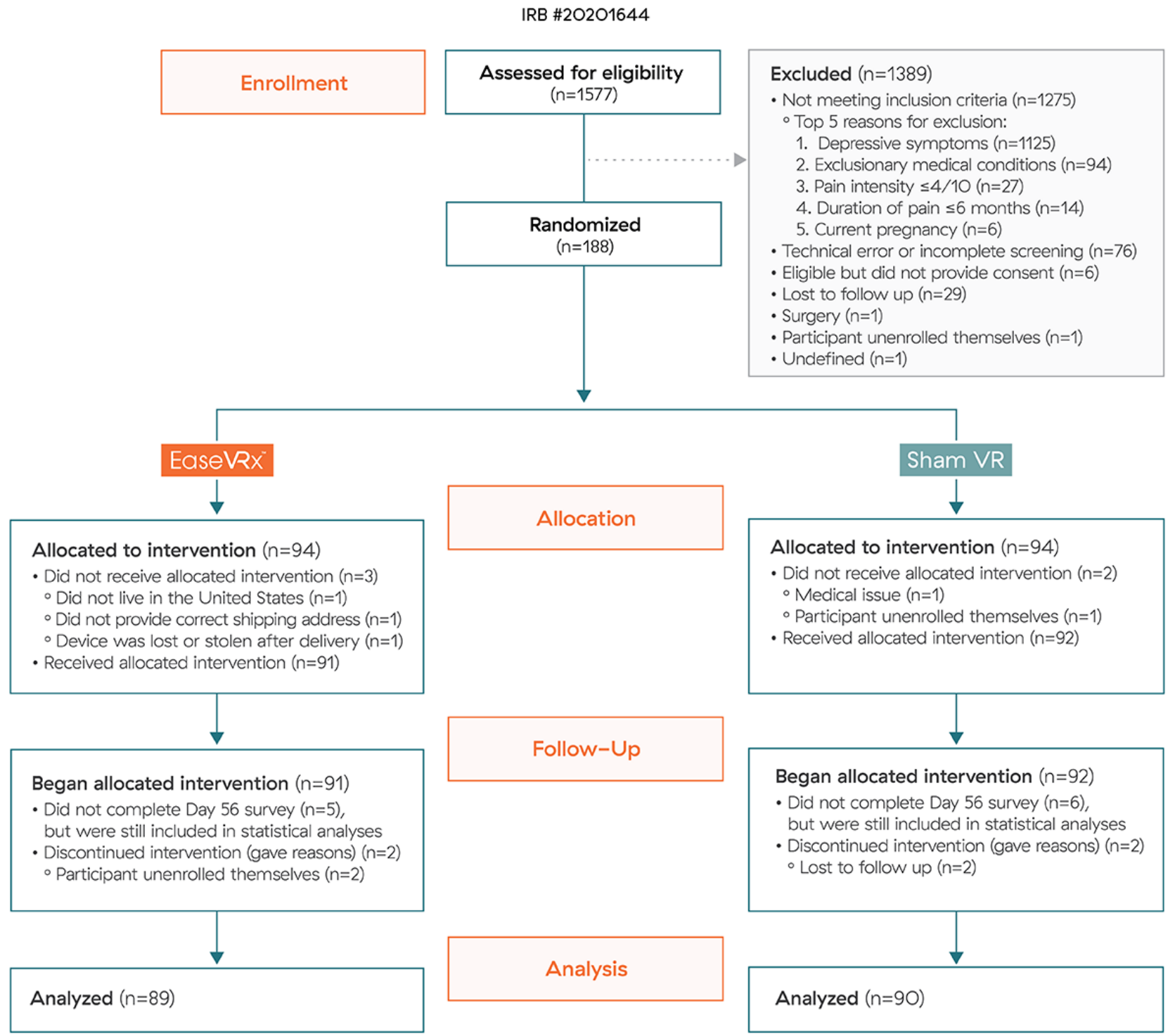

Table 2 displays the baseline demographic characteristics by treatment group. The sample included 179 participants from 40 states. RUCA codes were applied to categorize participants by zip code. In total, $76.5 \%(\mathrm{n}=137)$ resided in highly urban or metropolitan areas, $13.4 \% \quad(n=24)$ participants resided in metropolitan or micropolitan areas, $9.5 \%(n=17)$ were from small town or rural areas, and $0.6 \%(n=1)$ had no rural-urban identifier information. The sample was predominantly female (76.5\%, 137/179), Caucasian $(90.5 \%, 162 / 179)$, with at least some college education $(91.1 \%, 163 / 179)$, and a mean age of 51.5 years (SD 13.1; range 18-81). No significant between-group differences were observed for any demographic variable, thus demonstrating that randomization was effective.

Table 3 presents the baseline pain and clinical characteristics for the sample by treatment group. The sample duration of back pain was 5 or more years, and the mean pain intensity score was 5/10 (SD 1.2; range 1-9). No significant differences were observed between treatment groups for all variables assessed. 
Table 2. Baseline demographic characteristics by treatment group.

\begin{tabular}{|c|c|c|c|}
\hline \multirow[t]{2}{*}{ Demographics } & \multicolumn{3}{|l|}{ Treatment group } \\
\hline & EaseVRx $(\mathrm{N}=89)$ & Sham VR ${ }^{\mathrm{a}}(\mathrm{N}=90)$ & $P$-value \\
\hline Gender, n (\%) & & & $.527^{\mathrm{b}}$ \\
\hline Male & $22(25)$ & $19(21)$ & \\
\hline Female & $67(75)$ & $70(78)$ & \\
\hline Other & $0(0)$ & $1(1)$ & \\
\hline Age (years) & & & $.964^{\mathrm{c}}$ \\
\hline Mean (SD) & $51.5(13.5)$ & $51.4(12.9)$ & \\
\hline Range & $18.0-81.0$ & $25.0-81.0$ & \\
\hline Median (IQR) & $51.0(40.0-62.0)$ & $54.0(41.0-62.0)$ & \\
\hline Race, n (\%) & & & $.247^{\mathrm{b}}$ \\
\hline Asian & $2(2)$ & $1(1)$ & \\
\hline Caucasian & $78(88)$ & $84(93)$ & \\
\hline African American & $5(6)$ & $1(1)$ & \\
\hline Multiracial & $2(2)$ & $3(3)$ & \\
\hline Other & $2(2)$ & $0(0)$ & \\
\hline Missing & $0(0)$ & $1(1)$ & \\
\hline Education, n (\%) & & & $.142^{\mathrm{b}}$ \\
\hline High-school graduate & $6(7)$ & $9(10)$ & \\
\hline Some college & $21(24)$ & $17(19)$ & \\
\hline Associate & $10(11)$ & $16(18)$ & \\
\hline Undergraduate & $17(19)$ & $25(28)$ & \\
\hline Postgraduate & $35(39)$ & $22(24)$ & \\
\hline Missing & $0(0)$ & $1(1)$ & \\
\hline Employment status, n (\%) & & & $.781^{\mathrm{b}}$ \\
\hline Part-time & $9(10)$ & $7(8)$ & \\
\hline Full-time & $37(42)$ & $34(38)$ & \\
\hline Not working & $13(15)$ & $10(11)$ & \\
\hline Retired & $15(17)$ & $20(22)$ & \\
\hline Unable to work & $15(17)$ & $18(20)$ & \\
\hline Missing & $0(0)$ & $1(1)$ & \\
\hline Annual household income, n (\%) & & & $.665^{\mathrm{b}}$ \\
\hline$<$ US $\$ 40,000$ & $22(25)$ & $22(24)$ & \\
\hline US $\$ 40,000-U S \$ 59,999$ & $24(27)$ & $18(20)$ & \\
\hline US \$60,000-US $\$ 79,999$ & $16(18)$ & $18(20)$ & \\
\hline$\geq$ US $\$ 80,000$ & $26(29)$ & $32(36)$ & \\
\hline Missing & $1(1)$ & $0(0)$ & \\
\hline Marital status, n (\%) & & & $.605^{\mathrm{b}}$ \\
\hline Married/Civil union & $52(58)$ & $61(68)$ & \\
\hline Divorced/Widowed/Separated & $20(22)$ & $14(16)$ & \\
\hline Single & $10(11)$ & $10(11)$ & \\
\hline
\end{tabular}




\begin{tabular}{lll}
\hline Demographics & $\begin{array}{l}\text { Treatment group } \\
\text { EaseVRx }(\mathrm{N}=89)\end{array}$ & Sham $\mathrm{VR}^{\mathrm{a}}(\mathrm{N}=90)$ \\
\hline Cohabitating & $6(7)$ & $5(6)$ \\
Missing & $1(1)$ & $0(0)$ \\
\hline
\end{tabular}

${ }^{\mathrm{a}}$ VR: virtual reality.

${ }^{\mathrm{b}}$ Chi-square $P$-value.

${ }^{\mathrm{c}}$ Kruskal-Wallis $P$-value. 
Table 3. Baseline clinical variables by treatment group. ${ }^{\mathrm{a}}$

\begin{tabular}{|c|c|c|c|}
\hline \multirow[t]{2}{*}{ Variables } & \multicolumn{3}{|l|}{ Treatment group } \\
\hline & EaseVRx $(\mathrm{N}=89)$ & Sham VR ${ }^{b}(N=90)$ & $P$-value \\
\hline Pain duration, $\mathrm{n}(\%)$ & & & $.082^{\mathrm{c}}$ \\
\hline$<1$ year & $7(8)$ & $1(1)$ & \\
\hline 1 year to $<5$ years & $25(28)$ & $26(29)$ & \\
\hline 5 years to $<10$ years & $15(17)$ & $24(27)$ & \\
\hline$>10$ years & $42(47)$ & $39(43)$ & \\
\hline Average pain intensity & & & $.616^{\mathrm{d}}$ \\
\hline Mean (SD) & $5.1(1.2)$ & $5.2(1.1)$ & \\
\hline Range & $2.2-8.2$ & $2.8-7.8$ & \\
\hline Median (IQR) & $5.0(4.2-5.8)$ & $5.2(4.4-5.6)$ & \\
\hline Pain interference with activity & & & $.398^{\mathrm{d}}$ \\
\hline Mean (SD) & $5.3(1.8)$ & $5.5(1.5)$ & \\
\hline Range & $1.2-10.0$ & $1.0-8.8$ & \\
\hline Median (IQR) & $5.6(4.0-6.4)$ & $5.5(4.6-6.2)$ & \\
\hline Pain interference with mood & & & $.340^{\mathrm{d}}$ \\
\hline Mean (SD) & $4.5(2.1)$ & $4.7(2.0)$ & \\
\hline Range & $0.0-8.8$ & $0.2-9.6$ & \\
\hline Median (IQR) & $4.4(2.8-5.8)$ & $4.6(3.6-5.8)$ & \\
\hline Pain interference with sleep & & & $.281^{\mathrm{d}}$ \\
\hline Mean (SD) & $4.8(2.6)$ & $5.3(1.9)$ & \\
\hline Range & $0.0-10.0$ & $0.6-9.6$ & \\
\hline Median (IQR) & $5.0(3.0-7.0)$ & $5.4(3.8-6.4)$ & \\
\hline Pain interference with stress & & & $.852^{\mathrm{d}}$ \\
\hline Mean (SD) & $4.6(2.2)$ & $4.8(2.0)$ & \\
\hline Range & $0.0-10.0$ & $0.6-9.6$ & \\
\hline Median (IQR) & $4.8(3.0-6.4)$ & $5.0(3.4-6.2)$ & \\
\hline Pain self-efficacy & & & $.766^{\mathrm{d}}$ \\
\hline Mean (SD) & $3.0(1.5)$ & $3.0(1.2)$ & \\
\hline Range & $0.0-6.0$ & $0.0-6.0$ & \\
\hline Median (IQR) & $3.0(2.0-4.0)$ & $3.0(2.5-4.0)$ & \\
\hline Pain catastrophizing & & & $.977^{\mathrm{d}}$ \\
\hline Mean (SD) & $8.0(3.8)$ & $8.0(3.5)$ & \\
\hline Range & $0.0-16.0$ & $0.0-16.0$ & \\
\hline Median (IQR) & $8.0(5.0-11.0)$ & $7.0(5.0-11.0)$ & \\
\hline Physical function & & & $.276^{\mathrm{d}}$ \\
\hline Mean (SD) & $38.3(5.1)$ & $37.6(4.6)$ & \\
\hline Range & $21.0-48.9$ & $27.1-59.0$ & \\
\hline Median (IQR) & $37.6(35.0-41.2)$ & $37.6(35.0-40.2)$ & \\
\hline Chronic pain acceptance & & & $.708^{\mathrm{d}}$ \\
\hline Mean (SD) & $24.5(7.3)$ & $23.9(6.7)$ & \\
\hline
\end{tabular}




\begin{tabular}{|c|c|c|c|}
\hline \multirow[t]{2}{*}{ Variables } & \multicolumn{3}{|l|}{ Treatment group } \\
\hline & EaseVRx $(\mathrm{N}=89)$ & Sham VR ${ }^{b}(N=90)$ & $P$-value \\
\hline Range & $5.0-42.0$ & $7.0-47.0$ & \\
\hline Median (IQR) & $24.0(20.0-28.0)$ & $23.0(20.0-28.0)$ & \\
\hline Sleep disturbance & & & $.230^{\mathrm{d}}$ \\
\hline Mean (SD) & $56.7(5.2)$ & $57.6(4.4)$ & \\
\hline Range & $44.2-67.5$ & $45.5-69.0$ & \\
\hline Median (IQR) & $56.3(53.3-60.4)$ & $58.3(55.3-60.4)$ & \\
\hline Opioid use, n (\%) & $22(25)$ & $33(37)$ & .083 \\
\hline \multicolumn{3}{|c|}{ Opioid dose (daily morphine milligram equivalent) } & $.158^{\mathrm{d}}$ \\
\hline Mean (SD) & $25.2(106.2)$ & $15.3(41.1)$ & \\
\hline Range & $0.0-875.0$ & $0.0-300.0$ & \\
\hline Median (IQR) & $0.0(0.0-0.0)$ & $0.0(0.0-10.0)$ & \\
\hline OTC analgesic use, n (\%) & $61(69)$ & $55(61)$ & .320 \\
\hline
\end{tabular}

${ }^{\mathrm{a}}$ Baseline for the 5 pain variables (pain intensity, pain-related activity, mood, sleep, and stress interference) represents the average from 5 administrations in the pretreatment phase (days $-14,-10,-7,-3$, and 0 ).

${ }^{\mathrm{b}}$ VR: virtual reality.

${ }^{\mathrm{c}}$ Chi-square $P$-value.

${ }^{\mathrm{d}}$ Kruskal-Wallis $P$-value.

\section{Treatment Engagement}

Device use data revealed nonsignificant between-group differences for treatment engagement: EaseVRx participants completed a total of 43.30 (SD 15.91) experiences (average 5.4 per week) and Sham VR participants completed 48.06 (SD 24.78) experiences (average 6.0 per week).

\section{Device Safety and Adverse Events}

Of the 147 participants who completed the 1-month posttreatment survey, 7/72 (9.7\%) from the EaseVRx group and $5 / 75(6.7 \%)$ from the Sham VR group reported experiencing nausea and motion sickness during the treatment phase of the study $(P=.50)$. Participants were encouraged to contact study staff with any problems experienced during treatment; however, no participants contacted study staff to report adverse events of any type, including nausea and motion sickness.

\section{Primary Outcomes}

Common analyses and data visualization were applied for all primary outcomes. The $\mathrm{x}$-axis represents time (days), with days -14 to 0 averaged and labeled "day 7" to represent the pretreatment phase, days 1-55 were the active treatment phase, and day 56 was the end of treatment and the primary endpoint. The color bands represent the $95 \%$ CI values for the mean after correcting for multiple comparisons (Tukey-Kramer). Overlapping bands indicate nonsignificant treatment group differences ( $P$-value) of simple main effects within each time point. The corresponding model effects for each primary outcome are displayed in Figures 4-8. 
Figure 4. Average pain intensity.

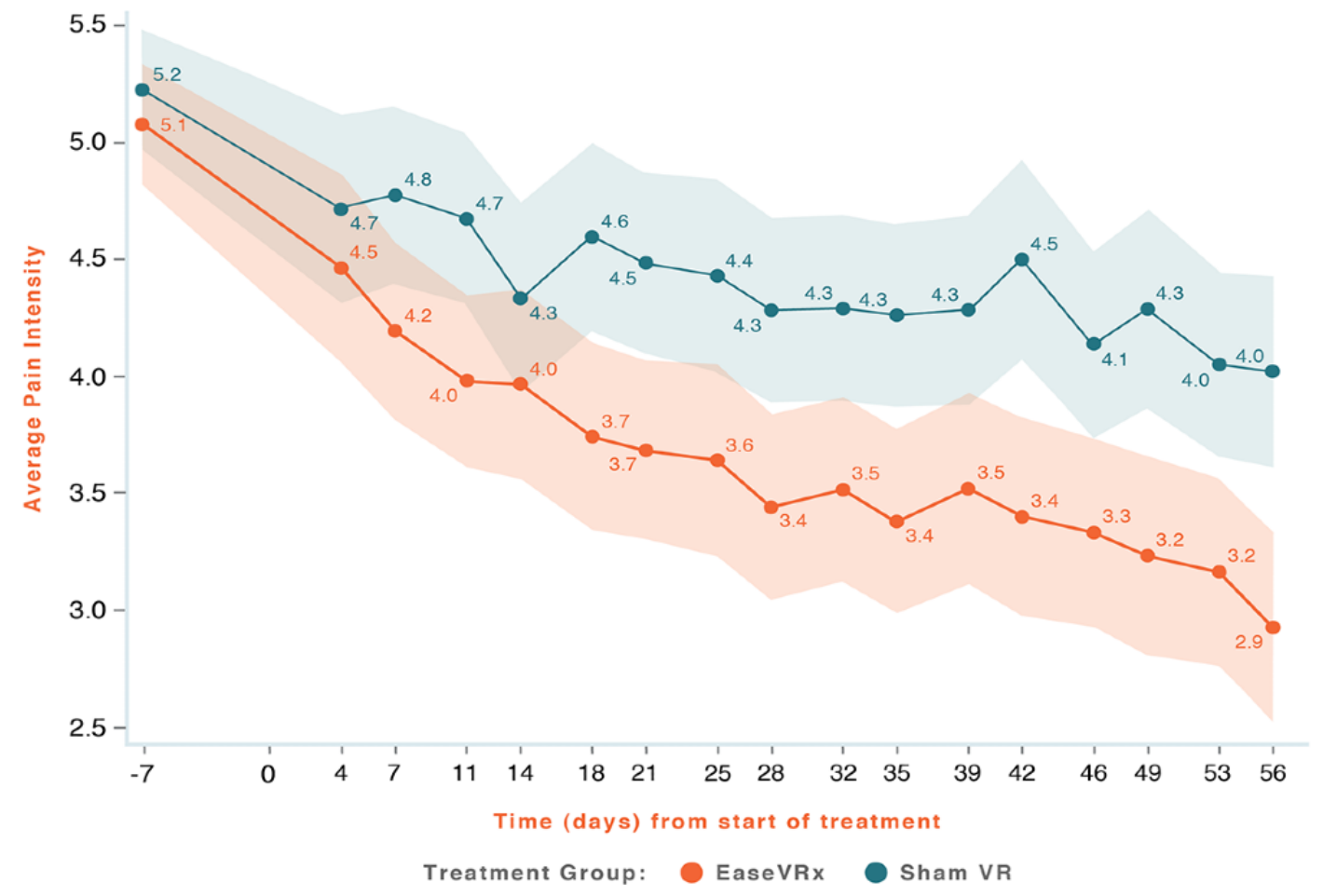

Figure 5. Pain-Related Interference with Activity.

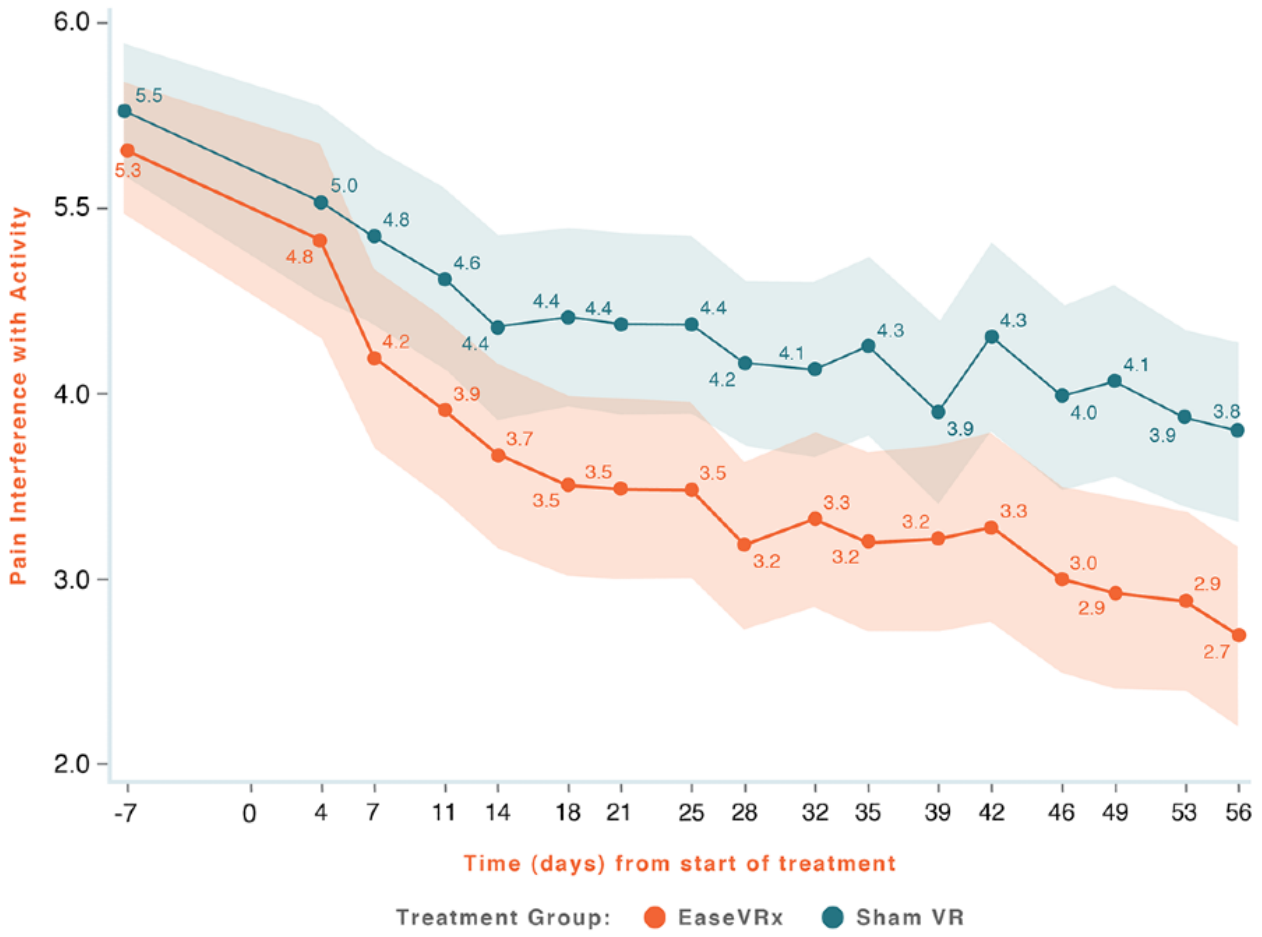


Figure 6. Pain-Related Interference with Mood.

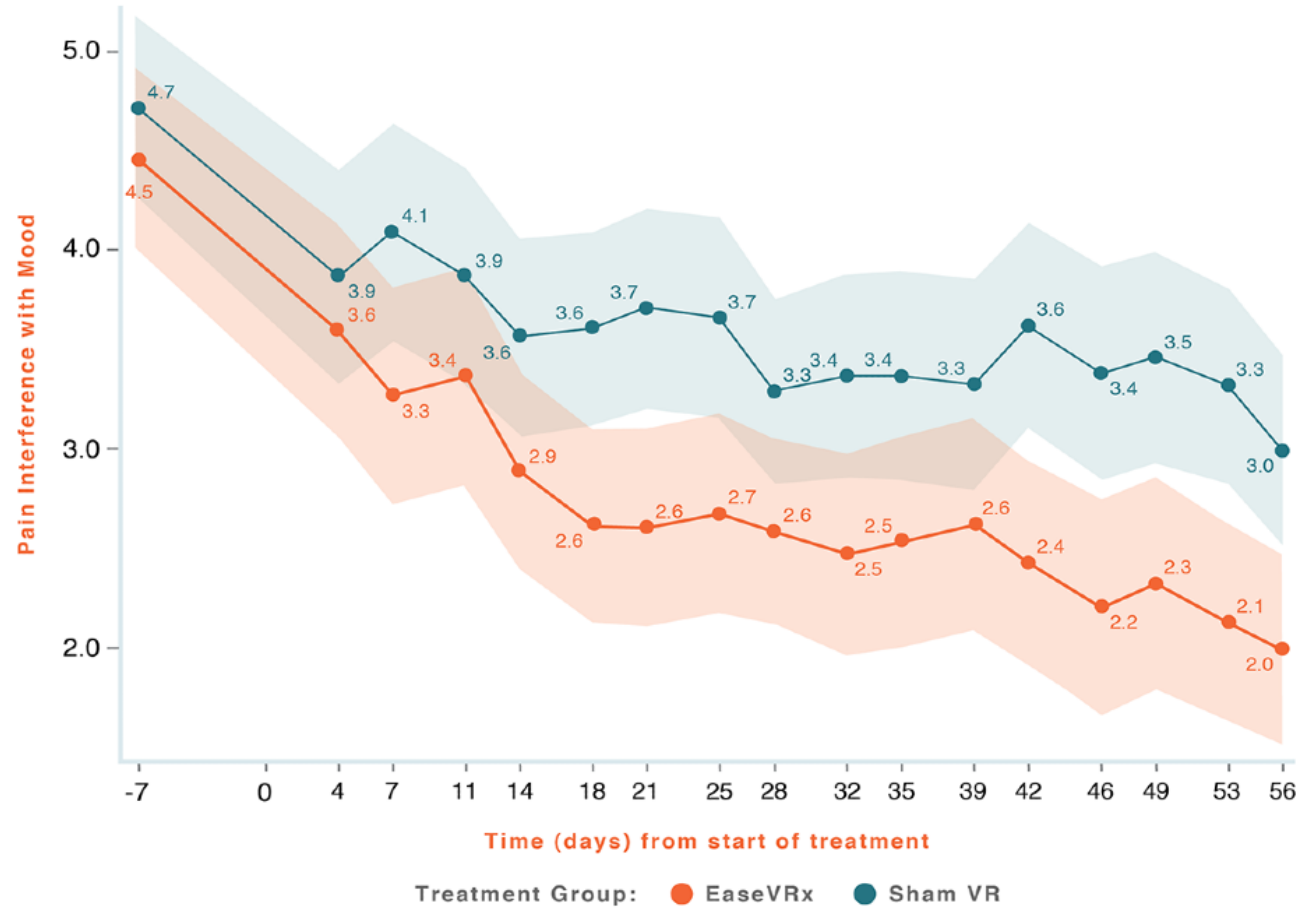

Figure 7. Pain Related Interference with Sleep.

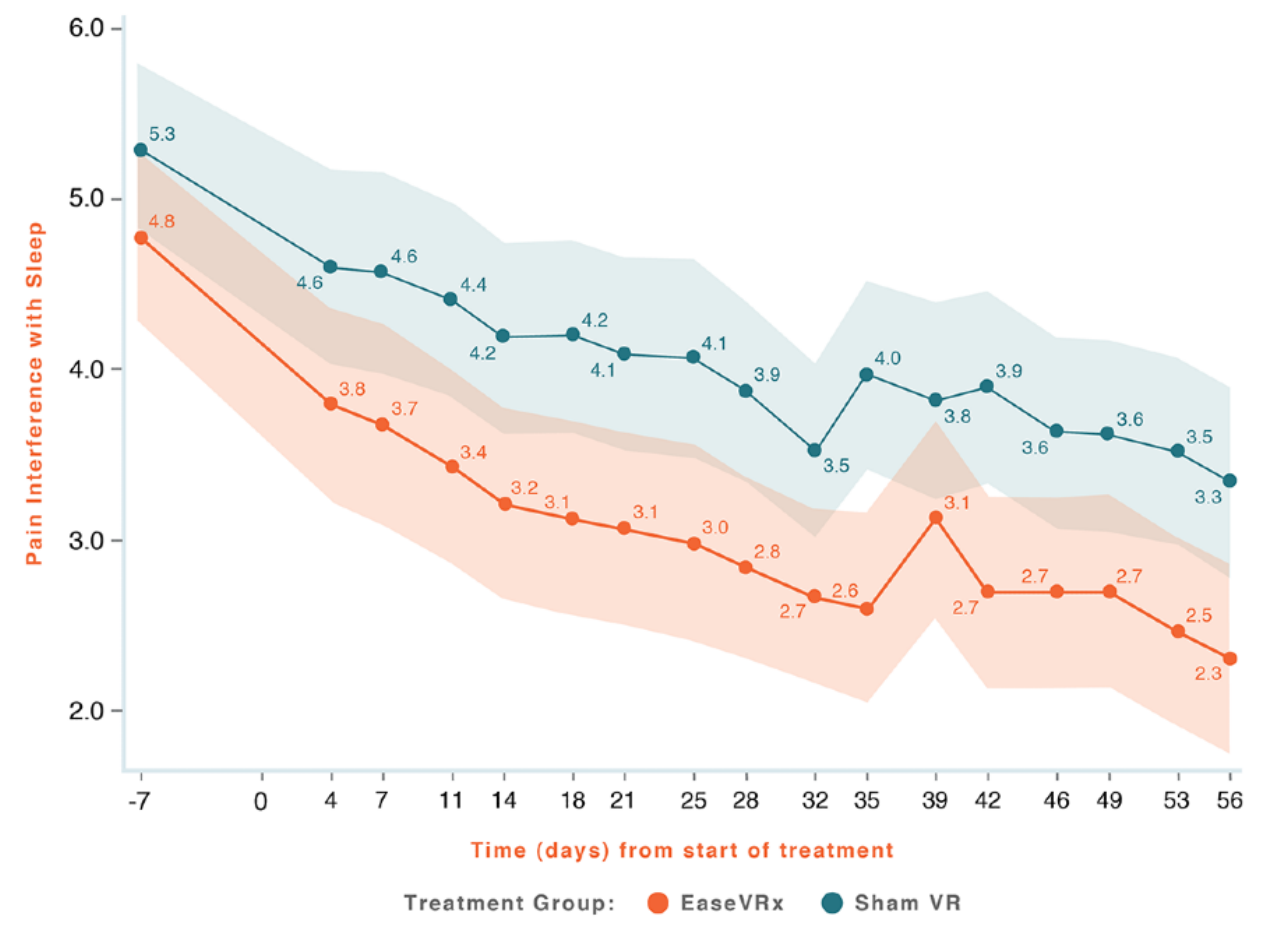


Figure 8. Pain-Related Interference with Stress.

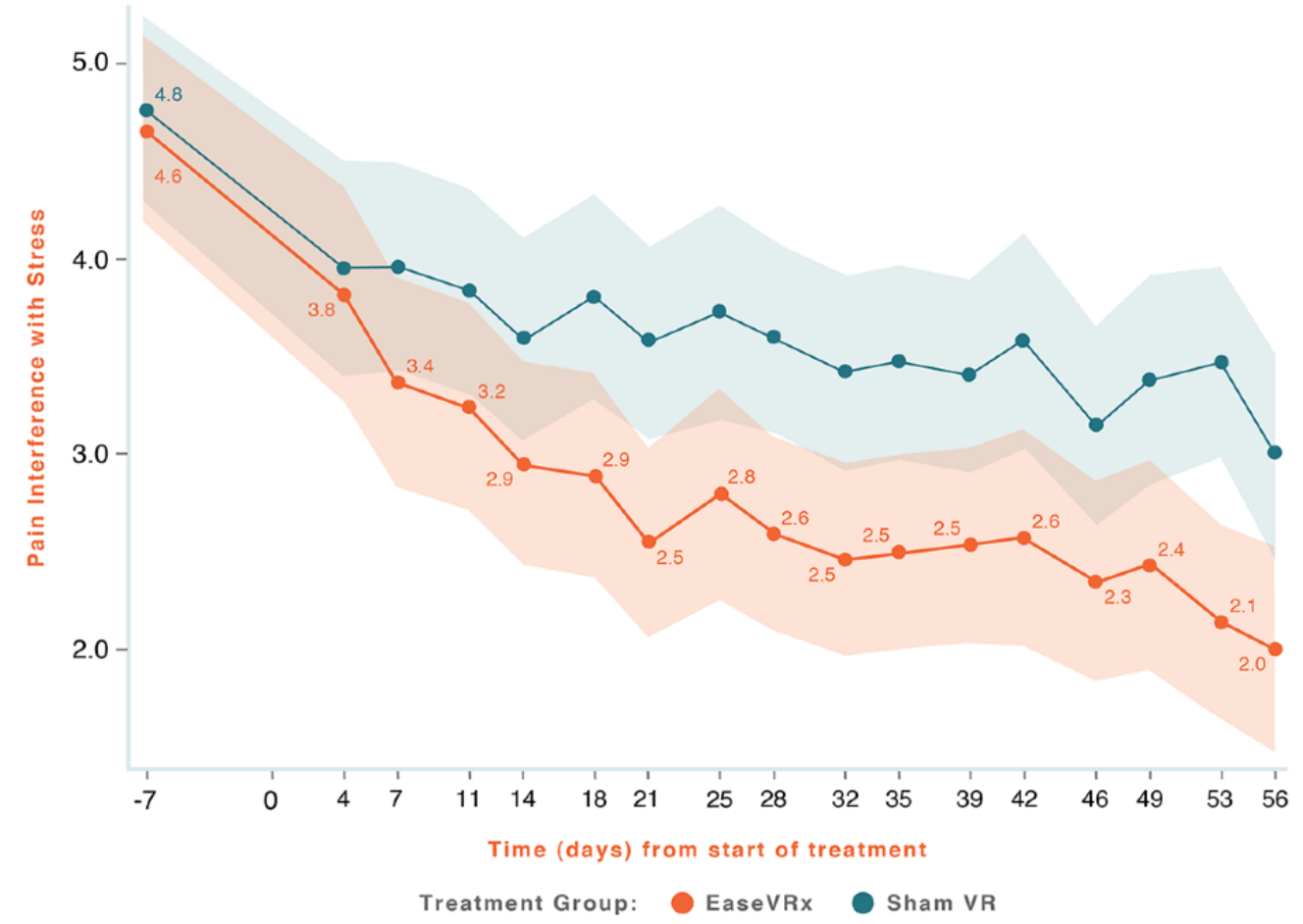

We observed a significant treatment effect $(P=.001)$; on average, the EaseVRx group had lower pain intensity compared to the Sham VR group (Cohen $d=0.49$ ). Separately, we observed a time effect; average pain intensity significantly decreased over time for both treatment groups (time effect, $P<.001$ ). Most importantly, the decrease was greater for EaseVRx versus Sham VR (treatment $\times$ time effect, $P<.001$ ). Pain intensity reduced by an average of $42.8 \%$ for the EaseVRx group and $25.1 \%$ for the Sham VR group. The $d_{r m}$ for EaseVRx was 1.31, with combined results showing large effect size and moderate clinical importance. The VR Sham group $d_{r m}$ was 0.75 , with combined results showing a large effect size and minimal clinical importance. As much as 65\% (55/84) of EaseVRx and $40 \%$ (34/84) of Sham VR participants achieved $30 \%$ or more reduction in pain intensity. For EaseVRx, 46\% (39/84) achieved $50 \%$ or more pain reduction, while for Sham VR 26\% (22/84) reached that threshold.

We observed a significant treatment effect $(P=.004)$ on pain interference with activity; on average, the EaseVRx group had lower activity interference compared to the Sham VR group (Cohen $d=0.44$ ). We also observed a time effect; pain interference with activity decreased over time for both treatment groups (time effect, $P<.001$ ). Most importantly, the decrease was greater for EaseVRx versus Sham VR (treatment $\times$ time effect, $P=.013$ ). Pain interference with activity reduced by an average of $51.6 \%$ for the EaseVRx group and $32.4 \%$ for the Sham VR group. The $d_{r m}$ for the EaseVRx group was 1.27 , with combined results showing large effect size and moderate clinical importance. As much as $71 \%(60 / 84)$ of EaseVRx and $57 \%$ $(48 / 84)$ of Sham VR participants achieved $30 \%$ or more reduction in pain-interference with activity, and $56 \%$ of (47/84) of the EaseVRx participants achieved $50 \%$ or more reduction. The VR Sham group $d_{r m}$ was 0.97 , with combined results showing a large effect size and moderate clinical importance.
We observed a significant treatment effect $(P=.005)$ on pain interference with mood; on average, the EaseVRx group had lower mood interference compared to the Sham VR group (Cohen $d=0.42$ ). We also observed a time effect; pain-interference with mood decreased over time for both treatment groups (time effect, $P<.001$ ) and the decrease was greater for EaseVRx versus Sham VR (treatment $\times$ time effect, $P=.010)$. Pain interference with mood reduced by an average of $55.7 \%$ for EaseVRx and $40.04 \%$ for the Sham VR. The $d_{r m}$ for the EaseVRx was 1.18, with combined results evidencing a large effect size and substantial clinical importance. As much as 74\% (62/84) of EaseVRx participants and 60\% (50/84) of Sham VR participants achieved $30 \%$ or more reduction in pain-related interference with mood, and $61 \%$ (51/84) of the EaseVRx participants achieved $50 \%$ or more reduction. The $d_{r m}$ for the VR Sham group was 0.79 , with combined results showing a moderate effect size and moderate clinical importance.

We observed a significant treatment effect $(P=.004)$ on pain-interference with sleep; on average, the EaseVRx group had lower sleep interference compared to the Sham VR group (Cohen $d=0.44)$. We also observed a time effect; pain-interference with sleep decreased over time for both treatment groups (time effect, $P<.001$ ). However, there was no difference between treatment groups over time $(P=.755)$. Pain interference with sleep reduced by an average of 54\% for EaseVRx and $39.2 \%$ for the Sham VR. The $d_{r m}$ for the EaseVRx was 0.95 , with combined results showing large effect size and substantial clinical importance for symptom reduction. As much as 70\% (59/84) of EaseVRx and 60\% (50/84) of participants achieved $30 \%$ or more reduction in Pain-related interference with sleep, and $60 \%(50 / 84)$ of the EaseVRx participants achieved $50 \%$ or more reduction. The VR Sham group $d_{r m}$ was 
0.87 , with combined results showing a large effect size and moderate clinical importance.

We observed a significant treatment effect $(P=.009)$ on pain interference with stress; on average, the EaseVRx group had lower stress interference compared to the Sham VR group (Cohen $d=0.40$ ). We also observed a time effect; pain interference with stress decreased over time for both treatment groups (time effect, $P<.001$ ). Most importantly, the decrease was greater for EaseVRx versus Sham VR (treatment $\times$ time effect, $P=.004$ ). Pain interference with stress reduced by an average of $59.9 \%$ for the EaseVRx group and $38.3 \%$ for the Sham VR group. The $d_{r m}$ for the EaseVRx was 1.17, with combined results evidencing a large effect size and substantial clinical importance. As much as 76\% (64/84) of EaseVRx participants and $56 \%(47 / 84)$ of the Sham VR participants achieved $30 \%$ or more reduction in pain-related interference with stress, and $63 \%$ (53/84) achieved $50 \%$ or more reduction. The VR Sham group $d_{r m}$ was 0.77 , with combined results showing a large effect size and moderate clinical importance.

\section{Secondary Outcomes}

\section{Treatment Engagement}

Device use data were received for 149 participants (EaseVRx =77; Sham VR =72). EaseVRx participants completed a mean of 43.3 (SD 15.9) sessions, while the Sham VR group completed a mean of 48.1 (SD 24.8) sessions. A significant group difference for treatment engagement was not found.

\section{Patient's Global Impression of Change}

\section{Between-Subjects Analysis}

The between-subjects analysis of PGIC at posttreatment indicated a significant effect of condition $(P=.002)$; participants in the EaseVRx group reported greater PGIC than those in the Sham VR group (4.13 versus 3.11).

While both groups evidenced improvement in pain coping symptoms, including pain catastrophizing, pain self-efficacy, and pain acceptance from pretreatment to end of treatment, none of these improvements achieved statistical significance.

\section{Physical Function}

For PROMIS Physical Function, we observed a significant treatment effect $(P=.022)$; the EaseVRx group had higher physical function compared to the Sham VR group (Cohen $d=0.34$ ). Both treatment groups significantly improved from baseline to postintervention; there was superior functional improvement for the EaseVRx group relative to the Sham VR group (time $\times$ condition effect, $P=.002$ ). The $d_{r m}$ values for the EaseVRx and VR Sham groups were 0.64 and 0.35 , respectively.

\section{Sleep Disturbance}

For PROMIS sleep disturbance, we observed a significant treatment effect $(P=.013)$; the EaseVRx group had lower sleep disturbance compared to the Sham VR group (Cohen $d=0.37$ ). Both treatment groups significantly improved throughout the study; there was superior improvement for the EaseVRx group relative to the Sham VR group (time $\times$ condition effect, $P=.035$ ).
The $d_{r m}$ for the EaseVRx group was 0.83, evidencing a large effect and substantial clinical importance.

\section{Prescription Opioid and OTC Analgesic Use}

Neither treatment group evidenced a significant change in MME dose from baseline to end of treatment. For OTC analgesic medication use, a substantial decrease was observed in the EaseVRx group. While 61 reported using OTC analgesics at baseline, 50 reported use at posttreatment day $56(P=.01)$. For Sham VR, 55 and 56 reported OTC analgesic use at baseline and posttreatment, respectively (nonsignificant).

\section{Treatment Satisfaction, Likelihood to Recommend, and Likelihood to Continue Use}

For the 4 summed satisfaction items, the EaseVRx group reported greater satisfaction with treatment than the Sham VR group (4.32 versus 3.46 respectively; $P<.001$ ). Similarly, the EaseVRx group reported greater likelihood to recommend VR to someone else compared to the Sham VR group ( 8.72 versus 6.55 , respectively; $P<.001)$. Finally, EaseVRx participants reported greater likelihood to continue using VR if they could keep their headset compared to Sham VR (9.18 versus 7.23, respectively; $P<.001)$.

\section{VR Usability Ratings}

Both treatment groups reported high usability with no statistical difference between groups (EaseVRx usability rating $=84.33$; Sham VR usability rating $=81.16)$.

\section{Additional Analyses}

Two additional Sham VR participants provided data for only 1 and 2 of the 16 surveys; including them in the analysis (for a total of 92) did not alter the significance of the study findings for any variable at any time point.

\section{Discussion}

\section{Principal Findings}

We conducted the first placebo-controlled RCT of home-based therapeutic VR in a national sample of individuals with cLBP. We hypothesized that an 8-week pain relief skills VR program (EaseVRx) would be superior to Sham VR at posttreatment (day 56) for our primary outcomes: average pain intensity and pain-related interference with activity, mood, sleep, and stress. While both study groups had significant reductions in pain and all domains of pain-related interference, EaseVRx evidenced superior treatment effects for all primary outcomes except sleep interference; the between-groups Cohen $d$ effect sizes ranged from 0.40 to 0.49. For EaseVRx, large pre/posttreatment Cohen $d$ effect sizes ranged from 1.17 to 1.3 and demonstrated moderate to substantial clinical importance for reduced pain intensity and pain-related interference with activity, mood, and stress at end of treatment. A greater proportion of participants in the EaseVRx group exceeded thresholds for clinical importance of effects. For moderate clinical importance in pain reduction ( $\geq 30 \%$ reduction in pain), 65\% (55 of 84) in EaseVRx versus $40 \%$ (34 of 84 ) in Sham VR met this threshold. For substantial clinical importance in pain reduction $(\geq 50 \%$ reduction in pain), $46 \%$ (39 of 84) in EaseVRx versus 26\% (22 
of 84) in Sham VR met this threshold. These effects for therapeutic VR exceeded effects reported for a 3-week skills-based VR program for chronic pain [15] and effects reported for CBT studies involving in-person 8-week treatment with a trained therapist $[4,6,7]$.

Both treatment groups evidenced moderate to substantial reductions for pain-related interference with sleep; however, no between group differences were found. By contrast, EaseVRx was superior to Sham VR for reducing sleep disturbance (secondary outcome), suggesting that therapeutic VR is particularly effective for reducing general versus pain-related sleep disturbance.

The secondary outcomes yielded interesting findings. First, physical function significantly improved for both treatment groups, with superior improvements found for EaseVRx. We note that the therapeutic content included no kinematic elements, nor did it include direction for activity, movement, or goal setting for either. Accordingly, improvement in physical function may be a product of substantially reduced pain-related interference in activity. Next, our hypothesis that therapeutic VR would be superior to Sham VR for improving pain coping (eg, reducing pain catastrophizing and improving pain self-efficacy and chronic pain acceptance) was unmet. The lack of effect for pain catastrophizing was particularly striking because this is a malleable construct that is highly responsive to behavioral treatments broadly [4,6,7] (Darnall et al, unpublished). However, our results align with the prior 3-week VR program study that similarly found no effect on pain catastrophizing and pain self-efficacy. Findings suggest that increased treatment time and additional focal content were insufficient to affect these factors significantly. These findings also highlight differences in treatment efficacy between therapeutic VR and CBT. Multiple studies have shown that CBT imparts its largest effect on pain catastrophizing [4]. By contrast, therapeutic VR evidenced its largest effects for reducing pain intensity and pain interference across several key domains.

We found no differences for either treatment group for change in prescription opioid use, and note that prescribing changes are unlikely to occur within the 2-month timeframe of the study. Similarly, we found no changes in "as needed" opioid use. We found substantially reduced use of OTC analgesic medication at posttreatment for the EaseVRx group only. While additional research is needed to replicate this finding, this finding offers a promising suggestion that therapeutic VR may reduce need for analgesics. Future VR research should examine medication use in greater detail and with higher-frequency data capture.

The study's methodologic rigor was strengthened by a placebo treatment (Sham VR), which evidenced equivalent participant engagement as therapeutic VR. The extant literature on digital behavioral health research has reported participant treatment engagement rates ranging from $20 \%$ to $60 \%$ [13,74-76]. Strikingly, the current trial evidenced a $90 \%$ engagement rate in both groups, thus suggesting that efforts to enhance the face validity of the Sham VR were effective. These results also highlight the public interest in home-based VR as a chronic pain treatment modality. Therapeutic VR was rated significantly higher than Sham VR for satisfaction, likelihood to recommend to others, and likelihood to continue using the device after the 8 -week treatment phase if it was made available. Combined with high participant engagement data and device usability ratings, these data extend prior work [15] supporting the utility, user satisfaction, and efficacy of home-based VR for chronic pain.

The context of the COVID-19 pandemic may have influenced the participant engagement rate. This trial occurred entirely at a time when people were adhering to strict social distancing measures and were environmentally isolated. Indeed, for many people receipt of medical care is worryingly low due to limited availability or unavailability of outpatient treatment options. These circumstances likely supported interest in effective home-based pain care. The COVID-19 context and the home-based study design support the ecological validity of the study findings. Notably, the study was conducted remotely and did not benefit from any in-person contacts or enhanced placebo effects that occur when research involves high-touch protocols or is conducted in medical treatment settings (ie, halo effects).

Strengths of this study include methods that attended to the IMMPACT recommendations and the NIH Research Standards for Back Pain. The study was conducted in a national sample drawn from 40 states, was well-distributed geographically, and included participants from urban and rural settings. Additional aspects of methodological rigor included participant and analyst blinding, intention-to-treat analyses, randomization, and a rigorous placebo control group that adhered to recommended specifications for an optimal VR sham [77].

\section{Limitations}

Several limitations bear consideration when evaluating the study results. With the exception of device use metrics, all data were self-reported. The study was untethered from medical care and thus, there was no ability to confirm pain diagnoses or analgesic prescription information. The study sample was predominantly female, white, college educated, and internet savvy; thus, findings may not generalize to individuals with disparate demographic characteristics. These findings are consistent with previous evidence showing that highly educated females are more likely to use self-care mobile health technologies, particularly those with mindfulness-based content [78], and this dovetails with a general female predilection to seek treatment for pain and other health concerns. As eHealth literacy and awareness increase in clinicians and the general population, it is likely that health technologies (including therapeutic VR) will benefit other demographics [79]. Additionally, the study was conducted in individuals with cLBP and findings may not generalize to other chronic pain conditions.

Data on cybersickness were collected at 1 month posttreatment and this lag introduces potential for recall bias, despite others documenting that participants readily recall cybersickness due to its specificity and salience [15]. Overall attrition was low $(n=11)$ and it is possible that the 2 EaseVRx participants who left the study after receiving their headset did so due to cybersickness. No participants contacted study staff to report adverse events of any type. Data on sex differences for cybersickness are mixed, with some reporting a female 
preponderance, while a recent meta-analysis suggests no sex effect [80]. Within the context of our limitations, we highlight low reports of cybersickness in a predominantly female sample. Future research may better capture potential VR adverse effects by assessing these factors in the first week of treatment. Interpretation of data on prescription opioid use was limited by low-frequency sampling methods that are subject to recall bias and poor data accuracy. Opioid prescriptions often allow "as needed" flexibilities in medication use and future research designs may benefit from high-frequency sampling methods which improve data accuracy. Further, in quantifying analgesic medication use (prescription opioids and OTC analgesics) we did not assess or control for life events or circumstances that may have influenced medication use (eg, acute injury or surgery). Finally, our threshold for depression screening and inclusion was applied to provide greater specificity [44] yet is noted to be lower than what is reported for many individuals with chronic pain. While our purpose in applying a low threshold for depressive symptoms was to minimize poor engagement and attrition resulting from anhedonia or avolition (and therefore poor data quality to determine treatment efficacy), recent research in cLBP suggests such concerns may be unfounded

\section{Acknowledgments}

AppliedVR, Inc supported this study. for mild to moderate depressive symptoms (Darnall et al, unpublished).

As a fully self-administered and on-demand treatment, VR is a promising and effective option that can transcend many traditional barriers to nonpharmacologic pain treatment; however, currently access is limited. With future reimbursement and commercial availability, therapeutic VR could become affordable and widely accessible to consumers.

\section{Conclusion}

An 8-week self-administered home-based pain relief skills VR program appears effective for reducing pain intensity and pain-related interference in activity, mood, and stress posttreatment. Treatment effects ranged from moderately to substantially clinically important. Therapeutic VR had high rates for engagement and user satisfaction. Additional studies are needed to determine effects in demographically diverse populations and in other pain conditions. Data suggest therapeutic VR is not operating through traditional pain coping mechanisms. As such, additional research is needed to characterize mechanisms of treatment effects and durability of effects. Home-based VR appears to provide effective and on-demand nonpharmacologic treatment for cLBP.

\section{Conflicts of Interest}

LG, TM, and IM are employees of AppliedVR, Inc. JS is president of AppliedVR, Inc. BD is chief science advisor for AppliedVR, Inc. BB, PK, and VS are consultants for AppliedVR, Inc. RL is a prior advisor and minor shareholder of AppliedVR, Inc.

\section{Multimedia Appendix 1}

eConsent form.

[PDF File (Adobe PDF File), 115 KB-Multimedia Appendix 1]

\section{Multimedia Appendix 2}

CONSORT-EHEALTH checklist (V.1.6.1).

[PDF File (Adobe PDF File), 380 KB-Multimedia Appendix 2]

\section{References}

1. Institute of Medicine (US) Committee on Advancing Pain Research, Care, and Education. Relieving Pain in America: A Blueprint for Transforming Prevention, Care, Education, and Research. Washington (DC): National Academies Press; 2011.

2. Freburger JK, Holmes GM, Agans RP, Jackman AM, Darter JD, Wallace AS, et al. The rising prevalence of chronic low back pain. Arch Intern Med 2009 Feb 09;169(3):251-258 [FREE Full text] [doi: 10.1001/archinternmed.2008.543] [Medline: 19204216]

3. Foster NE, Anema JR, Cherkin D, Chou R, Cohen SP, Gross DP, Lancet Low Back Pain Series Working Group. Prevention and treatment of low back pain: evidence, challenges, and promising directions. Lancet 2018 Jun 09;391(10137):2368-2383. [doi: 10.1016/S0140-6736(18)30489-6] [Medline: 29573872]

4. Williams A, Eccleston C, Morley S. Psychological therapies for the management of chronic pain (excluding headache) in adults. Cochrane Database Syst Rev 2012 Nov 14;11:CD007407 [FREE Full text] [doi: 10.1002/14651858.CD007407.pub3] [Medline: 23152245]

5. Medicaid Strategies for Non-Opioid Pharmacologic and NonPharmacologic Chronic Pain Management. 2019. URL: https:/ /www.medicaid.gov/sites/default/files/federal-policy-guidance/downloads/cib022219.pdf [accessed 2021-02-03]

6. Turner JA, Anderson ML, Balderson BH, Cook AJ, Sherman KJ, Cherkin DC. Mindfulness-based stress reduction and cognitive behavioral therapy for chronic low back pain: similar effects on mindfulness, catastrophizing, self-efficacy, and 
acceptance in a randomized controlled trial. Pain 2016 Nov 30;157(11):2434-2444 [FREE Full text] [doi: 10.1097/j.pain.0000000000000635] [Medline: 27257859]

7. Cherkin DC, Sherman KJ, Balderson BH, Cook AJ, Anderson ML, Hawkes RJ, et al. Effect of Mindfulness-Based Stress Reduction vs Cognitive Behavioral Therapy or Usual Care on Back Pain and Functional Limitations in Adults With Chronic Low Back Pain: A Randomized Clinical Trial. JAMA 2016 Mar 22;315(12):1240-1249 [FREE Full text] [doi: 10.1001/jama.2016.2323] [Medline: 27002445]

8. Darnall BD, Scheman J, Davin S, Burns JW, Murphy JL, Wilson AC, et al. Pain Psychology: A Global Needs Assessment and National Call to Action. Pain Med 2016 Feb 23;17(2):250-263 [FREE Full text] [doi: 10.1093/pm/pnv095] [Medline: 26803844]

9. Mojtabai R. National trends in long-term use of prescription opioids. Pharmacoepidemiol Drug Saf 2018 May 06;27(5):526-534. [doi: 10.1002/pds.4278] [Medline: 28879660]

10. Eccleston C, Blyth FM, Dear BF, Fisher EA, Keefe FJ, Lynch ME, et al. Managing patients with chronic pain during the COVID-19 outbreak: considerations for the rapid introduction of remotely supported (eHealth) pain management services. Pain 2020 May 2;161(5):889-893 [FREE Full text] [doi: 10.1097/j.pain.0000000000001885] [Medline: $\underline{32251203]}$

11. Fisher E, Law E, Palermo TM, Eccleston C. Psychological therapies (remotely delivered) for the management of chronic and recurrent pain in children and adolescents. Cochrane Database Syst Rev 2014 May 14;2014:CD011118 [FREE Full text] [doi: 10.1002/14651858.CD011118] [Medline: 25221436]

12. Ziadni M, Gonzalez-Castro LA, Darnall BD. Virtual Single-Session. 2020. URL: https://clinicaltrials.gov/ct2/show/ NCT04546685 [accessed 2021-02-03]

13. Darnall B, Ziadni MS, Krishnamurthy P, Flood P, Heathcote LC, Mackey IG, et al. "My Surgical Success": Effect of a Digital Behavioral Pain Medicine Intervention on Time to Opioid Cessation After Breast Cancer Surgery-A Pilot Randomized Controlled Clinical Trial. Pain Med 2019 Nov 01;20(11):2228-2237 [FREE Full text] [doi: 10.1093/pm/pnz094] [Medline: $\underline{31087093]}$

14. Pain Trainer. URL: https://www.paintrainer.org/ [accessed 2021-02-03]

15. Darnall BD, Krishnamurthy P, Tsuei J, Minor JD. Self-Administered Skills-Based Virtual Reality Intervention for Chronic Pain: Randomized Controlled Pilot Study. JMIR Form Res 2020 Jul 07;4(7):e17293 [FREE Full text] [doi: 10.2196/17293] [Medline: 32374272]

16. Navarro-Haro MV, Modrego-Alarcón M, Hoffman HG, López-Montoyo A, Navarro-Gil M, Montero-Marin J, et al. Evaluation of a Mindfulness-Based Intervention With and Without Virtual Reality Dialectical Behavior Therapy Mindfulness Skills Training for the Treatment of Generalized Anxiety Disorder in Primary Care: A Pilot Study. Front Psychol 2019 Jan 28;10:55 [FREE Full text] [doi: 10.3389/fpsyg.2019.00055] [Medline: 30745888]

17. Lindner P, Dagöö J, Hamilton W, Miloff A, Andersson G, Schill A, et al. Virtual Reality exposure therapy for public speaking anxiety in routine care: a single-subject effectiveness trial. Cogn Behav Ther 2021 Jan 01;50(1):67-87. [doi: 10.1080/16506073.2020.1795240] [Medline: 32870126]

18. Miloff A, Lindner P, Dafgård P, Deak S, Garke M, Hamilton W, et al. Automated virtual reality exposure therapy for spider phobia vs. in-vivo one-session treatment: A randomized non-inferiority trial. Behav Res Ther 2019 Jul;118:130-140. [doi: 10.1016/j.brat.2019.04.004] [Medline: 31075675]

19. Tejera D, Beltran-Alacreu H, Cano-de-la-Cuerda R, Leon Hernández JV, Martín-Pintado-Zugasti A, Calvo-Lobo C, et al. Effects of Virtual Reality versus Exercise on Pain, Functional, Somatosensory and Psychosocial Outcomes in Patients with Non-specific Chronic Neck Pain: A Randomized Clinical Trial. Int J Environ Res Public Health 2020 Aug 16;17(16):5950 [FREE Full text] [doi: 10.3390/ijerph17165950] [Medline: 32824394]

20. Hoffman HG, Richards T, Coda B, Richards A, Sharar SR. The illusion of presence in immersive virtual reality during an fMRI brain scan. Cyberpsychol Behav 2003 Apr;6(2):127-131. [doi: 10.1089/109493103321640310] [Medline: 12804024]

21. Gold JI, Belmont KA, Thomas DA. The neurobiology of virtual reality pain attenuation. Cyberpsychol Behav 2007 Aug;10(4):536-544. [doi: 10.1089/cpb.2007.9993] [Medline: 17711362]

22. Smith V, Warty RR, Sursas JA, Payne O, Nair A, Krishnan S, et al. The Effectiveness of Virtual Reality in Managing Acute Pain and Anxiety for Medical Inpatients: Systematic Review. J Med Internet Res 2020 Nov 02;22(11):e17980 [FREE Full text] [doi: 10.2196/17980] [Medline: $\underline{\text { 33136055] }}$

23. Gold J, Mahrer NE. Is Virtual Reality Ready for Prime Time in the Medical Space? A Randomized Control Trial of Pediatric Virtual Reality for Acute Procedural Pain Management. J Pediatr Psychol 2018 Apr 01;43(3):266-275. [doi:

10.1093/jpepsy/jsx129] [Medline: 29053848]

24. Atzori B, Hoffman HG, Vagnoli L, Patterson DR, Alhalabi W, Messeri A, et al. Virtual Reality Analgesia During Venipuncture in Pediatric Patients With Onco-Hematological Diseases. Front Psychol 2018 Dec 20;9:2508 [FREE Full text] [doi: 10.3389/fpsyg.2018.02508] [Medline: 30618938]

25. Atzori B, Lauro Grotto R, Giugni A, Calabrò M, Alhalabi W, Hoffman HG. Virtual Reality Analgesia for Pediatric Dental Patients. Front Psychol 2018 Nov 23;9:2265 [FREE Full text] [doi: 10.3389/fpsyg.2018.02265] [Medline: $\underline{30532720}$ ]

26. Gold JI, Kim SH, Kant AJ, Joseph MH, Rizzo A. Effectiveness of virtual reality for pediatric pain distraction during i.v. placement. Cyberpsychol Behav 2006 Apr;9(2):207-212. [doi: 10.1089/cpb.2006.9.207] [Medline: 16640481] 
27. Haisley KR, Straw OJ, Müller DT, Antiporda MA, Zihni AM, Reavis KM, et al. Feasibility of implementing a virtual reality program as an adjuvant tool for peri-operative pain control; Results of a randomized controlled trial in minimally invasive foregut surgery. Complement Ther Med 2020 Mar;49:102356. [doi: 10.1016/j.ctim.2020.102356] [Medline: 32147069]

28. Koç Özkan T, Polat F. The Effect of Virtual Reality and Kaleidoscope on Pain and Anxiety Levels During Venipuncture in Children. J Perianesth Nurs 2020 Apr;35(2):206-211. [doi: 10.1016/j.jopan.2019.08.010] [Medline: $\underline{31759833]}$

29. Hoffman HG, Chambers GT, Meyer WJ, Arceneaux LL, Russell WJ, Seibel EJ, et al. Virtual reality as an adjunctive non-pharmacologic analgesic for acute burn pain during medical procedures. Ann Behav Med 2011 Apr 25;41(2):183-191 [FREE Full text] [doi: 10.1007/s12160-010-9248-7] [Medline: 21264690]

30. Khadra C, Ballard A, Déry J, Paquin D, Fortin J, Perreault I, et al. Projector-based virtual reality dome environment for procedural pain and anxiety in young children with burn injuries: a pilot study. JPR 2018 Feb; Volume 11:343-353. [doi: 10.2147/jpr.s151084]

31. Spiegel B, Fuller G, Lopez M, Dupuy T, Noah B, Howard A, et al. Virtual reality for management of pain in hospitalized patients: A randomized comparative effectiveness trial. PLoS One 2019 Aug 14;14(8):e0219115 [FREE Full text] [doi: 10.1371/journal.pone.0219115] [Medline: $\underline{31412029}$ ]

32. Dascal J, Reid M, IsHak WW, Spiegel B, Recacho J, Rosen B, et al. Virtual Reality and Medical Inpatients: A Systematic Review of Randomized, Controlled Trials. Innov Clin Neurosci 2017;14(1-2):14-21 [FREE Full text] [Medline: 28386517]

33. Sato K, Fukumori S, Matsusaki T, Maruo T, Ishikawa S, Nishie H, et al. Nonimmersive virtual reality mirror visual feedback therapy and its application for the treatment of complex regional pain syndrome: an open-label pilot study. Pain Med 2010 Apr 01;11(4):622-629. [doi: 10.1111/j.1526-4637.2010.00819.x] [Medline: 20202141]

34. Shiri S, Feintuch U, Weiss N, Pustilnik A, Geffen T, Kay B, et al. A virtual reality system combined with biofeedback for treating pediatric chronic headache--a pilot study. Pain Med 2013 May 01;14(5):621-627. [doi: 10.1111/pme.12083] [Medline: 23659372]

35. Garcia-Palacios A, Herrero R, Vizcaíno Y, Belmonte MA, Castilla D, Molinari G, et al. Integrating Virtual Reality With Activity Management for the Treatment of Fibromyalgia. The Clinical Journal of Pain 2015;31(6):564-572. [doi: 10.1097/ajp.0000000000000196]

36. Herrero R, García-Palacios A, Castilla D, Molinari G, Botella C. Virtual reality for the induction of positive emotions in the treatment of fibromyalgia: a pilot study over acceptability, satisfaction, and the effect of virtual reality on mood. Cyberpsychol Behav Soc Netw 2014 Jun;17(6):379-384. [doi: 10.1089/cyber.2014.0052] [Medline: 24892201]

37. Sulea C, Soomro A, Boyd C, Wiederhold BK. Pain management in virtual reality: a comprehensive research chart. Cyberpsychol Behav Soc Netw 2014 Jun;17(6):402-413. [doi: 10.1089/cyber.2014.1514] [Medline: 24892205]

38. Wiederhold BK, Gao K, Sulea C, Wiederhold MD. Virtual reality as a distraction technique in chronic pain patients. Cyberpsychol Behav Soc Netw 2014 Jun;17(6):346-352 [FREE Full text] [doi: 10.1089/cyber.2014.0207] [Medline: 24892196]

39. Ahern M, Dean LV, Stoddard CC, Agrawal A, Kim K, Cook CE, et al. The Effectiveness of Virtual Reality in Patients With Spinal Pain: A Systematic Review and Meta-Analysis. Pain Pract 2020 Jul;20(6):656-675. [doi: 10.1111/papr.12885] [Medline: 32196892]

40. Gumaa M, Rehan Youssef A. Is Virtual Reality Effective in Orthopedic Rehabilitation? A Systematic Review and Meta-Analysis. Phys Ther 2019 Oct 28;99(10):1304-1325. [doi: 10.1093/ptj/pzz093] [Medline: $\underline{31343702]}$

41. Nambi G, Abdelbasset WK, Alrawaili SM, Alsubaie SF, Abodonya AM, Saleh AK. Virtual reality or isokinetic training; its effect on pain, kinesiophobia and serum stress hormones in chronic low back pain: A randomized controlled trial. THC 2021 Jan 15;29(1):155-166. [doi: 10.3233/thc-202301]

42. Nambi G, Abdelbasset WK, Elsayed SH, Alrawaili SM, Abodonya AM, Saleh AK, et al. Comparative Effects of Isokinetic Training and Virtual Reality Training on Sports Performances in University Football Players with Chronic Low Back Pain-Randomized Controlled Study. Evid Based Complement Alternat Med 2020 Jun 16;2020:2981273-2981210 [FREE Full text] [doi: 10.1155/2020/2981273] [Medline: 32617104$]$

43. Garcia LM, Darnall BD, Krishnamurthy P, Mackey IM, Sackman J, Louis R, et al. Self-Administered Behavioral Skills-Based At-Home Virtual Reality Therapy for Chronic Low Back Pain: Protocol for a Randomized Controlled Trial. JMIR Res Protoc 2021 Jan 19;10(1):e25291 [FREE Full text] [doi: 10.2196/25291] [Medline: 33464215]

44. Kroenke K, Spitzer RL, Williams JBW. The Patient Health Questionnaire-2. Medical Care 2003;41(11):1284-1292. [doi: 10.1097/01.mlr.0000093487.78664.3c]

45. Löwe B, Kroenke K, Gräfe K. Detecting and monitoring depression with a two-item questionnaire (PHQ-2). J Psychosom Res 2005 Feb;58(2):163-171. [doi: 10.1016/j.jpsychores.2004.09.006] [Medline: 15820844]

46. Dworkin R, Turk DC, Farrar JT, Haythornthwaite JA, Jensen MP, Katz NP, IMMPACT. Core outcome measures for chronic pain clinical trials: IMMPACT recommendations. Pain 2005 Jan;113(1-2):9-19. [doi: 10.1016/j.pain.2004.09.012] [Medline: 15621359]

47. Dworkin R, Turk DC, McDermott MP, Peirce-Sandner S, Burke LB, Cowan P, et al. Interpreting the clinical importance of group differences in chronic pain clinical trials: IMMPACT recommendations. Pain 2009 Dec;146(3):238-244. [doi: 10.1016/j.pain.2009.08.019] [Medline: 19836888] 
48. Turk DC, Dworkin RH, Burke LB, Gershon R, Rothman M, Scott J, et al. Developing patient-reported outcome measures for pain clinical trials: IMMPACT recommendations. Pain 2006 Dec 05;125(3):208-215. [doi: 10.1016/j.pain.2006.09.028] [Medline: 17069973]

49. Deyo RA, Dworkin SF, Amtmann D, Andersson G, Borenstein D, Carragee E, et al. Report of the NIH Task Force on research standards for chronic low back pain. Pain Med 2014 Aug 01;15(8):1249-1267. [doi: 10.1111/pme.12538] [Medline: 25132307]

50. Schulz KF, Altman DG, Moher D, CONSORT Group. CONSORT 2010 statement: updated guidelines for reporting parallel group randomised trials. PLoS Med 2010 Mar 24;7(3):e1000251 [FREE Full text] [doi: 10.1371/journal.pmed.1000251] [Medline: 20352064]

51. Grant S, CONSORT-SPI Group. The CONSORT-SPI 2018 extension: a new guideline for reporting social and psychological intervention trials. Addiction 2019 Jan 30;114(1):4-8. [doi: 10.1111/add.14411] [Medline: $\underline{30091280}$ ]

52. US Department of Agriculture. Rural-Urban Commuting Area Codes. URL: https://www.ers.usda.gov/data-products/ rural-urban-commuting-area-codes/ [accessed 2020-11-01]

53. Buckenmaier CC, Galloway KT, Polomano RC, McDuffie M, Kwon N, Gallagher RM. Preliminary validation of the Defense and Veterans Pain Rating Scale (DVPRS) in a military population. Pain Med 2013 Jan 01;14(1):110-123. [doi: 10.1111/j.1526-4637.2012.01516.x] [Medline: 23137169]

54. Nassif TH, Hull A, Holliday SB, Sullivan P, Sandbrink F. Concurrent Validity of the Defense and Veterans Pain Rating Scale in VA Outpatients. Pain Med 2015 Nov 01;16(11):2152-2161. [doi: 10.1111/pme.12866] [Medline: 26257151]

55. Amtmann D, Cook KF, Jensen MP, Chen WH, Choi S, Revicki D, et al. Development of a PROMIS item bank to measure pain interference. Pain 2010 Jul;150(1):173-182 [FREE Full text] [doi: 10.1016/j.pain.2010.04.025] [Medline: 20554116]

56. Fries JF, Krishnan E, Rose M, Lingala B, Bruce B. Improved responsiveness and reduced sample size requirements of PROMIS physical function scales with item response theory. Arthritis Res Ther 2011;13(5):R147 [FREE Full text] [doi: 10.1186/ar3461] [Medline: 21914216]

57. Yu L, Buysse DJ, Germain A, Moul DE, Stover A, Dodds NE, et al. Development of short forms from the PROMIS sleep disturbance and Sleep-Related Impairment item banks. Behav Sleep Med 2011 Dec 28;10(1):6-24 [FREE Full text] [doi: 10.1080/15402002.2012.636266] [Medline: 22250775]

58. Amtmann D, Cook KF, Johnson KL, Cella D. The PROMIS initiative: involvement of rehabilitation stakeholders in development and examples of applications in rehabilitation research. Arch Phys Med Rehabil 2011 Oct;92(10 Suppl):S12-S19 [FREE Full text] [doi: 10.1016/j.apmr.2011.04.025] [Medline: 21958918]

59. The Assessment Center. URL: https://www.assessmentcenter.net/ [accessed 2021-02-13]

60. Gershon RC, Rothrock N, Hanrahan R, Bass M, Cella D. The use of PROMIS and assessment center to deliver patient-reported outcome measures in clinical research. J Appl Meas 2010;11(3):304-314 [FREE Full text] [Medline: 20847477]

61. Varni JW, Magnus B, Stucky BD, Liu Y, Quinn H, Thissen D, et al. Psychometric properties of the PROMIS ® pediatric scales: precision, stability, and comparison of different scoring and administration options. Qual Life Res 2014 May 2;23(4):1233-1243 [ FREE Full text] [doi: 10.1007/s11136-013-0544-0] [Medline: 24085345]

62. Fischer HF, Rose M. Scoring Depression on a Common Metric: A Comparison of EAP Estimation, Plausible Value Imputation, and Full Bayesian IRT Modeling. Multivariate Behav Res 2019 Sep 20;54(1):85-99. [doi: 10.1080/00273171.2018.1491381] [Medline: 30235003]

63. Hung M, Baumhauer JF, Latt LD, Saltzman CL, SooHoo NF, Hunt KJ. Validation of PROMIS ® Physical Function computerized adaptive tests for orthopaedic foot and ankle outcome research. Clin Orthop Relat Res 2013 Nov;471(11):3466-3474 [FREE Full text] [doi: 10.1007/s11999-013-3097-1] [Medline: 23749433]

64. Sturgeon JA, Darnall BD, Kao MJ, Mackey SC. Physical and psychological correlates of fatigue and physical function: a Collaborative Health Outcomes Information Registry (CHOIR) study. J Pain 2015 Mar;16(3):291-8.e1 [FREE Full text] [doi: 10.1016/j.jpain.2014.12.004] [Medline: 25536536]

65. Sturgeon J, Dixon EA, Darnall BD, Mackey SC. Contributions of physical function and satisfaction with social roles to emotional distress in chronic pain: a Collaborative Health Outcomes Information Registry (CHOIR) study. Pain 2015 Dec;156(12):2627-2633 [FREE Full text] [doi: 10.1097/j.pain.0000000000000313] [Medline: 26230739]

66. Sullivan M, Bishop S, Pivik J. The Pain Catastrophizing Scale: Development and validation. Psychological Assessment 1995;7(4):524-532. [doi: 10.1037/1040-3590.7.4.524]

67. Darnall BD, Sturgeon JA, Cook KF, Taub CJ, Roy A, Burns JW, et al. Development and Validation of a Daily Pain Catastrophizing Scale. J Pain 2017 Sep;18(9):1139-1149 [FREE Full text] [doi: 10.1016/j.jpain.2017.05.003] [Medline: 28528981]

68. Nicholas MK, McGuire BE, Asghari A. A 2-item short form of the Pain Self-efficacy Questionnaire: development and psychometric evaluation of PSEQ-2. J Pain 2015 Feb;16(2):153-163. [doi: 10.1016/j.jpain.2014.11.002] [Medline: 25463701]

69. Fish R, McGuire B, Hogan M, Morrison TG, Stewart I. Validation of the chronic pain acceptance questionnaire (CPAQ) in an Internet sample and development and preliminary validation of the CPAQ-8. Pain 2010 Jun;149(3):435-443. [doi: 10.1016/j.pain.2009.12.016] [Medline: 20188472]

70. Brooke J. SUS: A 'Quick and Dirty' Usability Scale. In: Jordan PW, Thomas B, Weerdmeester BA, McClelland AL, editors. Usability Evaluation In Industry. London, UK: Taylor and Francis; 1996:189-194. 
71. Opioid Oral Morphine Milligram Equivalent (MME) Conversion Factors. 2017. URL: https://www.cms.gov/Medicare/ Prescription-Drug-coverage/PrescriptionDrugCovContra/Downloads/Opioid-Morphine-EQ-Conversion-Factors-Aug-2017. pdf [accessed 2021-02-03]

72. Rosenthal R, Rosnow RL. Essentials of Behavioral Research: Methods and Data Analysis (3rd edition). New York, NY: McGraw-Hill; 2008.

73. Lakens D. Calculating and reporting effect sizes to facilitate cumulative science: a practical primer for t-tests and ANOVAs. Front Psychol 2013 Nov 26;4:863 [FREE Full text] [doi: 10.3389/fpsyg.2013.00863] [Medline: 24324449]

74. Geraghty AWA, Torres LD, Leykin Y, Pérez-Stable EJ, Muñoz RF. Understanding attrition from international Internet health interventions: a step towards global eHealth. Health Promot Int 2013 Sep;28(3):442-452 [FREE Full text] [doi: 10.1093/heapro/das029] [Medline: 22786673]

75. Geraghty AWA, Wood AM, Hyland ME. Attrition from self-directed interventions: investigating the relationship between psychological predictors, intervention content and dropout from a body dissatisfaction intervention. Soc Sci Med 2010 Jul;71(1):30-37. [doi: 10.1016/j.socscimed.2010.03.007] [Medline: 20400220]

76. Eysenbach G. The law of attrition. J Med Internet Res 2005 Mar 31;7(1):e11 [FREE Full text] [doi: 10.2196/jmir.7.1.e11] [Medline: 15829473 ]

77. Birckhead B, Khalil C, Liu X, Conovitz S, Rizzo A, Danovitch I, et al. Recommendations for Methodology of Virtual Reality Clinical Trials in Health Care by an International Working Group: Iterative Study. JMIR Ment Health 2019 Jan 31;6(1):e11973 [FREE Full text] [doi: 10.2196/11973] [Medline: 30702436]

78. Gordon WJ, Landman A, Zhang H, Bates DW. Beyond validation: getting health apps into clinical practice. NPJ Digit Med 2020;3:14. [doi: 10.1038/s41746-019-0212-z] [Medline: 32047860]

79. Neter E, Brainin E. eHealth literacy: extending the digital divide to the realm of health information. J Med Internet Res 2012 Jan 27;14(1):e19 [FREE Full text] [doi: 10.2196/jmir.1619] [Medline: 22357448]

80. Saredakis D, Szpak A, Birckhead B, Keage HAD, Rizzo A, Loetscher T. Factors Associated With Virtual Reality Sickness in Head-Mounted Displays: A Systematic Review and Meta-Analysis. Front Hum Neurosci 2020;14:96 [FREE Full text] [doi: 10.3389/fnhum.2020.00096] [Medline: 32300295]

\author{
Abbreviations \\ CBT: cognitive behavioral therapy \\ cLBP: chronic low back pain \\ CPAQ-8: 8-item Chronic Pain Acceptance Questionnaire \\ DVPRS: Defense and Veterans Pain Rating Scale \\ MME: morphine milligram equivalent \\ OTC: over the counter \\ PCS: Pain Catastrophizing Scale \\ PGIC: Patient's Global Impression of Change \\ PROMIS: Physical Function and Sleep Disturbance \\ PSEQ-2: 2-item Pain Self-Efficacy Questionnaire \\ RCT: randomized controlled trial \\ RUCA: rural-urban commuting area \\ SUS: System Usability Scale \\ VR: virtual reality
}

Edited by G Eysenbach; submitted 23.12.20; peer-reviewed by M Linnett, T Jones, S Kardes, P Gazerani; comments to author 06.01.21;
revised version received 11.01.21; accepted 13.01.21; published 22.02.21
Please cite as:
Garcia LM, Birckhead BJ, Krishnamurthy P, Sackman J, Mackey IG, Louis RG, Salmasi V, Maddox T, Darnall BD
An 8 -Week Self-Administered At-Home Behavioral Skills-Based Virtual Reality Program for Chronic Low Back Pain: Double-Blind,
Randomized, Placebo-Controlled Trial Conducted During COVID-19
J Med Internet Res 2021;23(2):e26292
URL: $\underline{\text { https://www.jmir.org/2021/2/e26292 }}$
doi: $\underline{10.2196 / 26292}$
PMID: $\underline{33484240}$

CLaura M Garcia, Brandon J Birckhead, Parthasarathy Krishnamurthy, Josh Sackman, Ian G Mackey, Robert G Louis, Vafi Salmasi, Todd Maddox, Beth D Darnall. Originally published in the Journal of Medical Internet Research (http://www.jmir.org), 
22.02.2021. This is an open-access article distributed under the terms of the Creative Commons Attribution License (https://creativecommons.org/licenses/by/4.0/), which permits unrestricted use, distribution, and reproduction in any medium, provided the original work, first published in the Journal of Medical Internet Research, is properly cited. The complete bibliographic information, a link to the original publication on http://www.jmir.org/, as well as this copyright and license information must be included. 